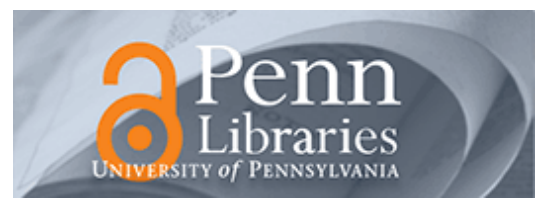

University of Pennsylvania

ScholarlyCommons

Management Papers

Wharton Faculty Research

$5-29-2014$

\title{
What's Love Got to Do With It? A Longitudinal Study of the Culture of Companionate Love and Employee and Client Outcomes in a Long-Term Care Setting
}

Sigal G. Barsade

University of Pennsylvania

Olivia A. O'Neill

Follow this and additional works at: https://repository.upenn.edu/mgmt_papers

Part of the Business Administration, Management, and Operations Commons, and the Human

Resources Management Commons

\section{Recommended Citation}

Barsade, S. G., \& O'Neill, O. A. (2014). What's Love Got to Do With It? A Longitudinal Study of the Culture of Companionate Love and Employee and Client Outcomes in a Long-Term Care Setting. Administrative Science Quarterly, 1-48. http://dx.doi.org/10.1177/0001839214538636

This paper is posted at ScholarlyCommons. https://repository.upenn.edu/mgmt_papers/79

For more information, please contact repository@pobox.upenn.edu. 


\title{
What's Love Got to Do With It? A Longitudinal Study of the Culture of Companionate Love and Employee and Client Outcomes in a Long-Term Care Setting
}

\begin{abstract}
In this longitudinal study, we build a theory of a culture of companionate love-feelings of affection, compassion, caring, and tenderness for others-at work, examining the culture's influence on outcomes for employees and the clients they serve in a long-term care setting. Using measures derived from outside observers, employees, family members, and cultural artifacts, we find that an emotional culture of companionate love at work positively relates to employees' satisfaction and teamwork and negatively relates to their absenteeism and emotional exhaustion. Employees' trait positive affectivity (trait PA)-one's tendency to have a pleasant emotional engagement with one's environment-moderates the influence of the culture of companionate love, amplifying its positive influence for employees higher in trait PA. We also find a positive association between a culture of companionate love and clients' outcomes, specifically, better patient mood, quality of life, satisfaction, and fewer trips to the emergency room. The study finds some association between a culture of love and families' satisfaction with the longterm care facility. We discuss the implications of a culture of companionate love for both cognitive and emotional theories of organizational culture. We also consider the relevance of a culture of companionate love in other industries and explore its managerial implications for the healthcare industry and beyond.
\end{abstract}

\section{Keywords}

affect, companionate love, emotional culture, long-term care industry, hospitals and healthcare, patient outcomes, job satisfaction, absenteeism

\section{Disciplines}

Business Administration, Management, and Operations | Human Resources Management 


\title{
WHAT'S LOVE GOT TO DO WITH IT? A LONGITUDINAL STUDY OF THE CULTURE OF COMPANIONATE LOVE AND EMPLOYEE AND CLIENT OUTCOMES IN THE LONG- TERM CARE SETTING
}

\author{
Sigal G. Barsade \\ Wharton School \\ University of Pennsylvania \\ Suite 2000, Steinberg-Dietrich Hall \\ Philadelphia, PA 19106 \\ (215) 898-1373 \\ barsade@wharton.upenn.edu \\ Olivia A. O’Neill \\ School of Management \\ George Mason University \\ 4400 University Drive MS 5F5 \\ Fairfax, VA 22032 \\ (703) 993-4216 \\ ooneill@gmu.edu
}

In Press, Administrative Science Quarterly

Authorship is alphabetical - both authors contributed equally to the manuscript. Many thanks to Charles O'Reilly, Nancy Rothbard, and Barry Staw for their insightful comments, and to research assistants Alina Ispas, Daniel Milner, Karishma Sabhnani, Dayna Shi, Julia Sodbinow, and Chia Tsay for their help. We are grateful to Audrey Weiner, Orah Burack and Michael Lubetkin of JLCC for their unwavering support of this project. We thank the Wharton Center for Leadership and Change and the Wharton Center for Human Resources for their generous financial support of this study. 


\title{
WHAT'S LOVE GOT TO DO WITH IT? A LONGITUDINAL STUDY OF THE CULTURE OF COMPANIONATE LOVE AND EMPLOYEE AND CLIENT OUTCOMES IN THE LONG- TERM CARE SETTING
}

\begin{abstract}
Companionate love is a basic human emotion that has been largely neglected within the domain of organizational behavior. In this longitudinal study, we build a theory of a culture of companionate love, examining the culture's influence on outcomes for employees and the clients they serve in a long-term care setting. Using outside observer, employee and family member measures, we find that a culture of companionate love positively relates to employee satisfaction and teamwork and negatively relates to employee absenteeism and emotional exhaustion. Employee trait positive affect moderates the influence of the culture of companionate love, amplifying its positive influence for employees higher in trait PA. We also find a positive association between a culture of companionate love and client outcomes, specifically, better patient mood, quality of life, satisfaction, and fewer trips to the emergency room. The study finds some association between a culture of love and family satisfaction with the long-term care facility. Exploratory analyses indicated a relationship between a culture of companionate love artifacts and employee outcomes. We discuss the implications of a culture of companionate love for both emotions and organizational culture theory. We also consider the relevance of a culture of companionate love in other industries and explore its managerial implications for the healthcare industry and beyond.
\end{abstract}


A revolution within the organizational behavior literature in the past 25 years revealed the importance of emotions for employee attitudes, interpersonal relations, and performance at work (Barsade and Gibson, 2007). However, so far this revolution has left at least two domains by the wayside. The first is research into the basic human emotion of companionate love, defined as feelings of affection, compassion, caring, and tenderness for others (Walster and Walster, 1978; Shaver et al., 1987; Fehr, 1988; Fehr and Russell, 1991; Lazarus, 1991). This lack of research is a problem because-in contrast to the assumption that love stops at the office door, or that work relationships are not deep enough to be called "love"- the history of the organizational behavior field is rich with evidence that love is fundamental to understanding the full breadth of employees' emotional experiences in organizations (Sheldon, 1923; Roethlisberger and Dickson, 1939). Contemporary organizations, too, are repositories of meaningful connections and otheroriented emotions (Fineman, 2000). Thus, given the importance of both work and companionate love in people's lives, it is important to understand the influence of companionate love on workplace outcomes.

A second neglected domain in the study of emotions relates to one of the field's most important collective phenomena: organizational culture. Several streams of innovative research have incorporated the study of emotions in individual behavior and group dynamics, thus deepening our understanding of these constructs (Brief and Weiss, 2002; Elfenbein, 2007). Yet the broader collective phenomenon of organizational culture has not yet integrated emotions in a meaningful way. This oversight has significant implications: it limits our understanding of the ways organizational culture can be expressed and transferred among employees as well as the ways organizational culture can influence workplace outcomes. In this study, we integrate these two research domains, companionate love and organizational culture. We do so in a quantitative longitudinal study of the influence of a culture of companionate love in the long-term care industry. Through this work, we aim to advance research in the organizational behavior field by shining a light on the under-studied basic human emotion of companionate love, and to offer a new and more complete paradigm for future research in organizational culture.

\section{What is Companionate Love?}

"Love" is a word rarely found in the modern management literature. Yet for more than half a century psychologists have studied companionate love as a basic emotion fundamental to the human 
experience (Walster and Walster, 1978; Reis and Aron, 2008). Companionate love is a far less intense emotion than its conceptual cousin, romantic love (Hatfield and Rapson, 1993, 2000); instead of passion, it is based on warmth, connection (Fehr, 1988; Sternberg, 1988), and the "affection we feel for those with whom our lives are deeply intertwined" (Berscheid and Walster, 1978, p.177; Reis and Aron, 2008). Unlike "self-focused" positive emotions (such as pride or joy), which center on independence and self-orientation, companionate love is an "other-focused" emotion, promoting interdependence and sensitivity toward other people (Markus and Kitayama, 1991; Gonzaga et al., 2001). Therefore, evolutionary explanations of companionate love describe it as a way to strengthen social bonds, helping to keep people connected and committed (Reis and Aron, 2008). As in the general definition of emotions, the construct of companionate love can consist of facial expressions, vocal tone, body language, touch, physiological sensations, subjective experience, cognitive appraisal, and behavioral action tendencies (Lasswell and Lasswell, 1976; Kleinginna and Kleinginna, 1981; Hertenstein et al., 2006).

With its focus on others and interdependence, companionate love is a social emotion (Gonzaga et al., 2001) that is shaped by social context (Watson, 1930). Therefore, it is particularly relevant to consider the impact of companionate love in the workplace at a collective level, including the level of organizational culture. Doing so not only contributes to our understanding of the nature of love at work, but it also offers a more complete view of the organizational culture construct. Although organizational culture research has generated a multitude of organizational research since its inception over 30 years ago (Smircich, 1983; Frost et al., 1991; Schein, 2010; Ashkanasy, Wilderom, and Peterson, 2011), a critical aspect of culture, the emotional content of organizational culture, what we call "emotional culture," has been neglected. Rather, the literature to date has conceptualized organizational culture almost exclusively from a cognitive perspective, as “a set of cognitions shared by members of a social unit” (Rousseau, 1990; O’Reilly, Chatman, and Caldwell, 1991). We question this conceptualization of culture, which we call "cognitive culture," as too narrow given the way culture is typically understood within other social sciences. Leading scholars in anthropology (Rosaldo, 1984; Lutz, 1988), sociology (Durkheim, [1912] 1965; Goffman, 1959), and psychology (Markus and Kitayama, 1991; Keltner and Haidt, 1999) include explicit references to the 
emotional nature of culture. As Geertz (1973:81), for instance, famously stated, "Not only ideas, but emotions too, are cultural artifacts.”

Focusing on emotional culture allows us to see crucial elements that are not visible through the study of cognitive culture alone. To date the organizational culture literature has largely neglected emotions. The few instances in which emotions are mentioned typically describe how sharing a strong cognitive culture leads employees to feel good (O'Reilly and Chatman, 1996). In this way, emotions are merely an outcome variable, indistinguishable from employee attitudes such as job satisfaction or organizational commitment. There is no organizational culture theory that incorporates behavioral norms, values and deep underlying assumptions about the content of the emotions themselves, and the way these aspects of culture lead to differential outcomes for employees and the organization. This omission is problematic because basic research in the social sciences and affective studies in organizational behavior have shown that emotions spread and influence outcomes differently than cognition does (Izard, Kagan, and Zajonc, 1988; Robinson, Watkins, and Harmon-Jones, 2013). These differences manifest themselves in the way that an emotional culture of companionate love will be expressed, the way it will be experienced and spread among employees, and the ways it will influence practical outcomes. To this end, we draw on classic and modern management research to build a theory of an emotional culture of companionate love and to develop hypotheses predicting the influence of a culture of companionate love on employees, patients, and patients' families in a long-term care setting.

\section{Theory of an Emotional Culture of Companionate Love}

What, indeed, has love got to do with it? As we noted earlier, companionate love has received less scholarly attention than other emotions, especially in the domain of organizational behavior. Some would say that this is as it should be, arguing either that work relationships are not sufficiently intimate to elicit such feelings, or that love is an emotion that is simply inappropriate in the work domain. However, considering the large proportion of our lives we spend with others at work (U.S. Bureau of Labor Statistics, 2011), and the influence of companionate love as documented in other varied life domains (Shaver et al., 1987), as well as the nascent but growing field of positive organizational scholarship that focuses on human connections at work (Rynes et al., 2012), it is reasonable to expect that this basic human emotion will not 
only exist at work but that it will also influence workplace outcomes. Indeed, when searching for evidence of the existence of companionate love among employees, one need look no further than the foundations of the organizational behavior field. Although the term "companionate love" had not yet been coined during the early history of the management discipline, classic work from early $20^{\text {th }}$ century organizational scholars revealed rich evidence of deep connections between workers involving the feelings of affection, caring and compassion that comprise companionate love. This tradition began as far back as Taylor (1911), who, although associated today with concerns for almost robotic efficiency, wrote in his famous monograph Scientific Management about the importance of caring and intimacy among workers and between workers and supervisors. He noted that workers appreciated "small acts of personal kindness and sympathy..." (p. 184) and observed that "each girl was made to feel that she was the object of special care" (p. 94). Similar observations were made a decade later by Sheldon (1923), who advocated for "sympathetic management" (p. 80), defined by “fellowship, sentiment, softness" (p. 147). Rexford Hersey's (1932) groundbreaking daily experience sampling study of Pennsylvania Railroad System employees also recorded the importance of caring, affection, compassion and tenderness_-as well as highlighting the negative effects when these emotions were absent. For example, Hersey describes a situation in which a foreman expressed caring and compassion by helping an employee who lost an arm in an accident, and comments on the situation: "It is such interest and appreciation of their workers' difficulties which make men admire and like to work for certain foremen, while they despise others for their lack of consideration" (p.199).

The human relations movement built on these early ideas about the importance of deep emotional connections among employees in each other's work lives. Roethlisberger and Dickson's (1939) detailed and well-cited study of factory life, Management and the Worker, provided crisp observations of companionate love interspersed among descriptions of worker interactions. These scholars described supervisors who showed genuine affection, care, compassion and tenderness towards their employees.

Despite clear evidence from early 20th century management theorists of employees showing affection and care in deeply intertwined work relationships, companionate love largely disappeared from the management literature in subsequent decades, as organizational theorists moved away from the study of a broad range of emotional experiences to an almost exclusive focus on the narrow and mostly cognitive 
construct of job satisfaction (Brief and Weiss, 2002). Moreover, even though the "affective revolution" in organizational behavior (Barsade, Brief, and Spataro, 2003) offered a return to a more complete examination of the many emotions people experience at work, organizational theorists ceased examining companionate love in the workplace. We aim to revive the study of this basic human emotion at work, doing so at the collective, cultural level— thereby offering a more complete picture of organizational culture, as well. Strong versus Weak Cultures of Companionate Love. To picture a strong culture of companionate love, first imagine a pair of co-workers collaborating side by side, each day expressing caring and affection towards one another, safeguarding each other's feelings, showing tenderness and compassion when things don't go well and supporting each other in work and non-work matters. Then expand this image to an entire network of dyadic and group interactions so that this type of caring, affection, tenderness and compassion occurs frequently within most of the dyads and groups throughout the entire social unit: a clear picture emerges of a culture of companionate love. Such a culture involves high "crystallization," that is, pervasiveness or consensus among employees in enacting the culture (Jackson, 1966). An example of high crystallization appears in a qualitative study of social workers (Kahn, 1993) in which compassion (one of the subcomponents of companionate love) spreads through the network of employees in a "flow and reverse flow" of the emotion from employees to one another and to supervisors and back. One employee said, "I let them see how much I care about them," and recipients of this caring felt that "there's a real warmth there" (p. 546). This crystallization of companionate love can cross organizational levels; for example, at the Medical Center of Aurora, one employee described the pervasiveness of companionate love throughout the unit: "We are a family. When you walk in the door, you can feel it. Everyone cares for each other regardless of whatever level you are in. We all watch out for each other" (Medical Center of Aurora, 2013). Words like "all" and "everyone" in conjunction with affection, caring and compassion are hallmarks of a high crystallization culture of companionate love.

Another characteristic of a strong culture of companionate love is a high degree of displayed intensity (Jackson, 1966) of emotional expression of affection, caring, compassion and tenderness. This can be seen in the example of an employee diagnosed with Multiple Sclerosis who described a work group whose members treated her with tremendous companionate love during her daily struggles with the 
condition. "My secretary tried to help me through the injection herself, and even brought me roses and orange juice and bagels. I still couldn't do it. At that point my coworkers arranged for outpatient nurses to help me... My coworkers showed me more love and compassion than I would ever have imagined. Do I wish that I didn't have MS? Of course. But would I give up the opportunity to witness and receive so much love? No way.” (Lilius et al., 2005). An even more broad manifestation of a culture of companionate love can be seen at Barry-Wehmiller, a $\$ 1.5$ billion global equipment and engineering consulting company. After losing $40 \%$ of their orders, the CEO decided that rather than laying off some employees, every single employee in the company would take a four-week furlough. The CEO, Bob Chapman, described employees' responses: “The reaction was extraordinary. Some team members offered to take double furloughs, stepping up to 'take the time' for their co-workers who could not afford the loss of pay. ... Our decision to use furloughs to save jobs made our associates proud and profoundly touched by the realization that they worked for a company that truly cared about them. ... they embraced the furlough program because it meant saving someone else's job” (Chapman, 2013).

In weak cultures of companionate love, on the other hand, expressions of affection, caring, compassion or tenderness among employees are minimal or non-existent—showing both low intensity and low crystallization. Instead of these emotions, employees in cultures low in companionate love show indifference or even callousness toward each other. Employees in such cultures do not offer or expect the emotions that comprise companionate love when things are going well and do not allow room to deal with distress in the workplace when things are not going well. In a recent hospital case study, when a nurse with 30 years of tenure told her supervisor that her mother-in-law had died, her supervisor responded not with compassion or even sympathy, but by saying, "I have staff that handles this. I don't want to deal with it" (Lilius et al. 2008: 209). Contrast this reaction with one from the billing unit of a health services organization where an employee described her co-workers' reactions following the death of her mother this way: "I did not expect any of the compassion and sympathy and the love, the actual love that I got from co-workers" (Lilius et al., 2011: 880).

The Structure of a Culture of Companionate Love. From a structural perspective, it is common to characterize organizational culture at various levels of abstraction (Schein, 1990; Trice and Beyer, 1993; Hall 
et al., 1997). To date, these structural levels of abstraction have only been used to describe cognitive cultural content, but they nonetheless offer a useful way of thinking about how an emotional culture of companionate love would be structured. At its most topical level—the level that is visible to employees and outsiders alike — companionate love is expressed and transmitted primarily through facial expression, body language, vocal tone and touch (Hatfield and Rapson, 1993; Hatfield et al., 1995; Gonzaga et al., 2001; Hertenstein et al., 2006). For example, a nurse working with HIV/AIDS patients described the importance of touch in communicating caring: "hugs when you enter, hugs when you leave" (Miller, 2007). Indeed, emotions in general are primarily communicated through nonverbal channels (Mehrabian, 1972) and a culture of companionate love will be expressed and transmitted primarily in this way. The ability to detect and recognize nonverbal emotional expressions is an inborn and universal adaptation that forms the basis for social communication (Malatesta and Haviland, 1982) and has been found to be nearly automatic in typical everyday interactions (Tracy and Robins, 2008). One implication of this is a difference in way emotional culture spreads and operates relative to cognitive culture. Whereas the topical level is often viewed as the most tertiary level in cognitive culture (Schein, 1991), outwardly visible nonverbal expressions of emotion are critical for understanding how the culture of companionate love spreads and operates, and are as important or more important than any of the other structural levels we describe below.

Although nonverbal emotional expressions serve as the primary visible manifestation of a culture of companionate love, at its most topical level, such a culture can also reveal itself in other ways. This would include verbal expressions of emotions, such as when employees talk about loving or caring for their coworkers as we described above. Another way is through cultural artifacts such as physical space and objects, artwork and decorations (Bechky, 2003; Rafaeli and Vilnai-Yavetz, 2004), as well as through stories and group rituals, rites, and ceremonies (Trice and Beyer, 1993; Schein, 2010). A good example of companionate love cultural artifacts can be found in Southwest Airlines, a company with a strong culture of companionate love, which has a well-known heart logo and "LUV" as its ticker symbol on the New York Stock Exchange.

At the next structural level, which is not as easily visible to outsiders of the group, an emotional culture of companionate love can be manifested through values that can be recognized and articulated by 
employees and that reflect the collective importance placed on expression or suppression of affection, caring, compassion, and tenderness. These values can be either descriptive or prescriptive. Descriptive values show what type of emotional culture is actually being expressed in the organization (Cialdini, Kallgren, and Reno, 1991). Values can also be prescriptive, or aspirational, reflecting espoused values that may or may not match the reality of the emotional culture as it is enacted among employees.

At its deepest structural level — the level that is most difficult to articulate or observe — the emotional culture of companionate love can manifest itself in the form of underlying assumptions about the meaning of expressing or suppressing the feelings of companionate love within the organization. Basic assumptions reflect the often implicit, taken-for-granted nature of this level of culture. The main underlying assumption of a strong culture of companionate love is that showing caring, affection, tenderness and affection for people at work is a natural part of what being at work means. A related assumption is that showing such emotions makes one a good employee. In contrast, people in a weak culture of companionate love assume that showing caring, compassion, tenderness, and affection is unnecessary and possibly even inappropriate. Such expressions are considered to be a waste (Turnbull, 1972) or a sign of weakness and dependence (Bartolomé, 1972; Solomon, 1988). This could be seen in a leader who wants to focus on "only the facts" and views companionate love as a sentimental emotion that would only cloud rational business thinking (Strati, 2005).

When a strong culture of companionate love meets a weak one, interesting clashes can occur, even within the same organization. For example, a newly acquired division of a large aerospace defense contractor had a strong culture of companionate love, as exemplified by employees of this division routinely greeting each other with a kiss on the cheek. Visiting corporate executives from the parent company were alarmed to see this gesture, finding it not only inappropriate at work, but even a possible invitation to sexual harassment lawsuits. Although the executives initially tried to prohibit such displays of companionate love, ultimately they decided to allow the culture to flourish within the division, simply acknowledging that it was not consistent with the more muted companionate love values expressed in the rest of the organization (First author, personal communication). This incident not only highlights the interplay among the three structural levels of culture (Hatch, 1993), it also highlights the fact that artifacts, values, and basic 
assumptions reflecting the worth of strong and weak cultures of companionate love can vary among social units within an organization, creating subcultures within the organization (Sackmann, 1992).

\section{Mechanisms of a Culture of Companionate Love: Feeling and Enacting the Emotion. When} considering only the structural aspect of organizational culture, the three-level hierarchy of cultural manifestations is relevant to both emotional and cognitive culture. What is unique to a culture of companionate love, however, is that the artifacts, values, and deep underlying assumptions that constitute the culture are composed of the emotions that comprise companionate love, that is, affection, caring, compassion and tenderness. This distinction is not simply a semantic difference in content, but rather forms the basis of a completely different set of mechanisms through which a culture of companionate love will be expressed, will spread among employees, and will subsequently influence employee and client outcomes. These mechanisms are based primarily on nonverbal and physiological cues and channels, which differentiate them from the more cerebral mechanisms through which cognitive culture - of which language is a primary transmitter (Schein, 1991) - operates. In essence, a culture of companionate love operates through shared feelings (or shared thoughts about feelings) rather than through shared cognitions (or shared thoughts about cognitions).

More specifically, the culture of companionate love will get translated into action and influence employee and work outcomes through two main mechanisms: "feeling mechanisms," whereby employees actually experience the feeling of companionate love, and "normative enactments," whereby they express companionate love merely to conform to group expectations. Feeling mechanisms can be activated in several ways. First, employees can internally generate the emotions of companionate love (Ashforth and Humphrey, 1993). This can happen in a particular workplace moment, such as the compassion experienced when a co-worker hears from a colleague who is having trouble at work (Fredrickson, 2013). Feeling mechanisms can also get triggered on a more regular basis. For example, an employee at one of the largest global hedge funds said in an interview, "I can't say enough how much I love the people that I work for and, at this point, you know, it doesn't always feel like work anymore. . .these people love you, and they really mean it" (Bridgewater website, 2012). 
Another way to generate genuine feelings of love among employees in a collective setting is through emotional contagion (Hatfield, Cacioppo, and Rapson, 1993), whereby employees "catch" the emotions of companionate love from other co-workers. Contagion is a largely subconscious process in which people actually feel the emotions they catch from others and view them as their own. This occurs through behavioral and auditory feedback: after mimicking the other person's facial expression, tone or body language, the individuals' own facial expressions or actions induce corresponding feelings (Strack, Martin, and Stepper, 1988; Hatfield et al., 1995). Emotional contagion has been found to be a prevalent group phenomenon for both negative and positive emotions (Barsade, 2002), including love (Hatfield, Cacioppo, and Rapson, 1993). Although the initial source of emotions is other people, emotional contagion leads employees to genuinely feel the companionate love they see other employees expressing as part of the culture.

Last, feeling mechanisms could come to be activated by "deep acting ${ }^{1}$," whereby employees consciously try to genuinely feel the emotion they are required to display at work (Grandey, 2003). For example, imagine an accountant at a client services firm who has a family emergency and requests two weeks off work at the height of tax audit season. Although his co-workers might initially be stressed and upset about the additional workload, employees in a culture of companionate love would engage in deep acting, leading to genuine feelings of compassion and "sympathy rituals" (Goffman, 1983), such as telling him, "Of course, you should go be with your family!” and not bothering him with work questions while he is away. This deep acting could be aided by the same facial, bodily and voice feedback discussed above, whereby enacting an emotion in one's own face, vocal tone or body language then leads one to feel the emotion, and to gain the psychological and psychological benefits of that emotion (Kraft and Pressman, 2012).

In addition to the feeling mechanisms described above, a culture of companionate love can influence employee and client outcomes through a secondary mechanism, normative enactment. Unlike the feeling mechanisms in which employees actually feel the emotions they are expressing, normative enactment

\footnotetext{
${ }^{1}$ Although previous organizational studies on deep and surface acting have focused almost exclusively on interactions between employees and clients or customers (rather than among employees themselves), these forms of emotion regulation have been shown to be relevant among employee interactions as well (Diefendorff and Richard, 2006; Ozcelik, 2013).
} 
keeps people conforming to group expectations regardless of how they actually feel (Levy, 1973). The idea underlying this mechanism is that, in addition to expressing genuine and spontaneous emotions, people also express emotions strategically and intentionally (Parkinson, 2005). In early anthropological studies of group rituals, culturally derived emotions were found to facilitate group cohesion by overpowering individual feelings and synchronizing interpersonal behavior (Durkheim, [1912] 1965; Turner, 1967). Goffman (1959), too, argued that maintaining positive social interactions in a group requires cultural scripts for socially acceptable emotions — scripts that disregard what actors may truly be feeling. This body of work highlights one category of normative enactment—surface acting — in which employees display emotions they do not feel but are required to express as part of their job (Hochschild, 1983; Ashforth and Humphrey, 1993). Surface acting is similar to the broader construct of display rules (Ekman, 1973; Rafaeli and Sutton, 1987), informal norms or rules that govern the appropriateness of expressing certain emotions in everyday situations. Normative enactment can also include expressing emotions as a form of affective social exchange, or emotional reciprocity (Clark, 1997), such as when a co-worker's consolation for another colleague's work performance engenders a sense of obligation or pressure to "repay" them at some point in the future. Individuals might also conform to group norms of emotional expression through social influence (Sherif, 1936; Asch, 1955), imitating others' emotions because of a desire to be liked and accepted by the group.

Because of the force of the normative mechanism, employees in a culture of companionate love who would not otherwise be inclined toward feeling and expressing love will begin to engage in such emotional expressions - even if their motive is compliance rather than internalization of the culture (Kelman, 1958). As one health services employee put it, "If you came to work at this place and you weren't as compassionate a person as others ... I think it just becomes a part of your norm if it wasn't before. If you practice it enough, it becomes the norm” (Lilius et al., 2011: 881). In other words, employees do not actually have to feel the emotions for positive individual and group outcomes to occur, but they do need to enact them.

We expect the two sets of mechanisms in the culture of companionate love — feeling mechanisms and normative enactments — to be reciprocally linked through feedback processes, creating an emotion 
cycle (Hareli and Rafaeli, 2008). Feeling the emotion can lead employees to enact and enforce the norms of a culture of companionate love more vigorously. Similarly, employees who start out expressing companionate love only to conform to the culture's norms will likely feel the emotion through emotional contagion; for instance, by expressing companionate love because it is expected, employees actually come to feel this emotion, which can elicit a change in the physiology of the brain, leading employees to be more likely to enact the emotion again (Weng et al., 2013). Thus, there could be many avenues for reinforcement of the feelings of a culture of companionate love.

Combining the defining characteristics of a strong culture of companionate love with the proposed underlying mechanisms, we define an emotional culture of companionate love as the behavioral norms and artifacts, as well as the underlying values and assumptions, reflecting the actual expression or suppression of affection, caring, compassion and tenderness, and the degree of perceived appropriateness of these emotions, transmitted through feeling and normative mechanisms within a social unit.

\section{The Influence of a Culture of Companionate Love on Employee, Patient and Family Outcomes in the Long-Term Care Setting}

Classic management texts and some of the more recent management literature have recorded evidence of companionate love at work across many industries, as we have seen. But perhaps no industry has supported the importance of companionate love for its employees as much as the healthcare industry, which includes organizations providing long-term patient care. Long-term care settings have been described as "a world of emotions" (Ruckdeschel and Van Haitsma, 2004:45), consisting primarily of the emotions of “caring” (Jacques, 1993; Scott et al., 1995), “affection” (Tetz et al., 2006), and “compassion” (Von Dietze and Org, 2000; Miller, 2007). These other-oriented emotions that are so prevalent in the long-term care context fit squarely within the construct of companionate love (Shaver et al. 1987; Berscheid and Walster, 1974). Among healthcare employees, loving relationships have been described as so essential at work that "they are part of, rather than separate from, work interactions" (Kahn, 1998:43). Therefore, we focus on the long-term care industry in our examination of the influence of companionate love. Through a longitudinal study of units in a long-term care organization, we examine the influence of a culture of companionate love not only on employee outcomes, but also on the culture's cascading effects on patients and their families. 


\section{The Effects of a Culture of Companionate Love on Employee Attitudes and Behavior. To}

understand the influence of an emotional culture of companionate love in the healthcare context, we first draw from cultural anthropology, where many studies have taken a functional-adaptational approach to culture. That is, researchers have found that culture arises from a specific historical or social context (Turner, 1967; Geertz, 1973) and exists because it is valuable to individual and group functioning and survival (Malinowski, 1944; White, 1949). This view corresponds to the similarly functional and adaptational role of emotions in general (Nesse, 1990), which anthropologists have noted can be understood, felt, and publicly expressed in a given culture to create desired societal outcomes (Levy, 1973; Rosaldo, 1984; Lutz, 1988). Cultural and evolutionary psychologists also adopt this approach, arguing that the expression of emotions can offer solutions to problems as well as opportunities for the group's success (Keltner and Haidt, 1999; Keltner and Gross, 1999). From a functional perspective, a culture of companionate love would offer individuals an appropriate way to fulfill their responsibility of mutual caring for other group members (Parkinson, Fischer, and Manstead, 2005).

In applying this functional-adaptational view to our setting, we consider what positive outcomes are most likely to arise from a culture of companionate love. To do so, we draw on recent research which argues that employee behaviors can be broadly classified as involving either withdrawal from or engagement with the work context: withdrawing from the work environment or engaging with others at work by making “desirable contributions" (Harrison, Newman, and Roth, 2006). Because a strong culture of companionate love is based on interactions with others in the environment, this is a useful way of thinking about the influence of companionate love on employee outcomes in the long-term care setting.

Employee withdrawal from work: Decreased emotional exhaustion and absenteeism. Employee emotional exhaustion, also known as burnout, is a type of workplace withdrawal that involves feeling depleted and overextended by one's work, most commonly by interpersonal work transactions (Maslach and Jackson, 1981). Employees in the care-giving professions are particularly prone to emotional exhaustion (Cherniss, 1980). Although emotional exhaustion is often discussed as an individual-level phenomenon, entirely dependent on the maintenance or depletion of individual resources (Hobfoll and Shirom, 2001), evidence 
suggests that caring among employees helps build interpersonal resources that can help employees cope with and even reverse the negative effects of emotional exhaustion (Kahn, 1993; Scott et al., 1995).

In contrast to this idea that feeling companionate love can protect against burnout, the organizational behavior literature has traditionally viewed almost all emotional normative enactments as leading to negative outcomes (Hochschild, 1983; Van Maanen and Kunda, 1989; Grandey, 2003). However, recent empirical research indicates that the relationship between workplace outcomes and employees enacting emotions they do not feel is more complex than first thought, and that whether employees' outcomes are positive or negative depends on the type of emotion and the characteristics of the people enacting them (e.g., Shuler and Syphur, 2000; Grandey, Fisk, and Steiner, 2005; Hayward and Tuckey, 2011). For example, across several different job types, enacting positive emotions_even if employees did not feel them—was associated with positive employee outcomes (Brotheridge and Grandey, 2002). One longitudinal study showed that employees who amplified the expression of pleasant emotions they did not feel subsequently experienced greater job satisfaction, whereas employees who dampened negative emotions they did feel experienced decreased job satisfaction (Coté and Morgan, 2002). Given this more updated theorizing and recent findings, we depart from early findings in the emotional labor literature, and predict: Hypothesis 1: A stronger culture of companionate love at Time 1 will be negatively associated with employee emotional exhaustion at Time 2.

A stronger culture of companionate love could also create physiological effects that reduce employee absenteeism. Feeling positive emotions has been shown to lead to better immune function (Boyatzis, Smith, and Blaize, 2006), easier physical recovery from work stresses (Heaphy and Dutton, 2008), and ultimately less absenteeism due to illness (Hackett, Bycio, and Guion, 1989). Employees in a strong culture of companionate love would also be more likely to enjoy being at work and wanting to spend time with co-workers. Recent empirical work supports this view, with a growing amount of evidence that an individual's absenteeism is tied to social and normative expectations (Hausknecht, Hiller, and Vance, 2008). The normative mechanism underlying a culture of companionate love would predict less absenteeism, as well. Because of the norms governing the social exchange of these emotions among employees, employees 
in a culture of companionate love are more likely to feel responsible for being at work, knowing that their absence will burden their colleagues with more tasks.

Hypothesis 2: A stronger culture of companionate love at Time 1 will be negatively associated with employee absenteeism at Time 2.

Culture of companionate love and employee engagement at work: Greater teamwork and satisfaction. A stronger culture of companionate love could lead to higher levels of teamwork through both genuinely felt emotions and normative enactments. From a biological perspective, feelings of love have been shown to be related to the hormone oxytocin. Recent studies indicate that oxytocin may be a biological driver of greater teamwork and satisfaction, helping in the recognition of facial expressions and trust (van IJzendoorn and BakermansKranenburg, 2012) and facilitating affectionate, intimate, and satisfying bonds between people (Kosfeld et al., 2005) that would facilitate teamwork. In addition, feeling companionate love could elicit an "othercentered" frame, that is, a focus on other people, which would likely lead employees to see themselves as more collectivistic and interdependent (Markus and Kitayama, 1991). Feelings of interdependence and collectivism are associated with greater cooperativeness and team orientation (Chatman and Barsade, 1995). Relatedly, employees may divert more toward stronger compassion-oriented goals (as compared to selfimage goals; Canevello and Crocker, 2010), which could then lead to a cycle of greater positive interpersonal responsiveness and, thus, enhanced teamwork.

Flowing from the normative mechanisms, a stronger culture of companionate love could also lead to better teamwork and satisfaction through the mutual reinforcement that comes from socio-emotional reciprocity (Clark, 1997). That is, the rules of social exchange (Lawler, 2001) —in this case, around the mutual expression of the components of companionate love-lead employees to reliably expect expressions of affection, caring, compassion and tenderness from one another. An example of this reciprocity can be seen in a study of "communities of coping" among neo-natal nurses in a special-care baby unit, in which emotional support among nurses came with a "tacit understanding that the offering of emotional support to colleagues is given on the basis of equal exchange" (Lewis, 2005: 577). As such, we hypothesize that:

Hypothesis 3: A stronger culture of companionate love at Time 1 will be positively associated with the level of teamwork at Time 2. 
Last, the interdependence that a culture of love fosters can also appeal to basic human needs, such as the need to affiliate with others (McClelland, 1958), and the need to feel attached to a group (Baumeister and Leary, 1995). When these basic needs are satisfied, individuals experience an increase in positive feelings. For example, hospital employees in an environment of greater compassion did actually come to feel greater positive emotions (Lilius et al., 2008). Following the logic of normative enactment, social exchange processes taking place within a strong culture of love could increase employee satisfaction by fostering strong relationship norms, which, in turn, increase psychological well-being among employees (Repetti, 1987). Coté and Morgan’s (2002) findings directly support the idea that the enhancement of pleasant emotions that are not necessarily felt nonetheless lead to greater job satisfaction.

Hypothesis 4: A stronger culture of companionate love at Time 1 will be positively associated with employee satisfaction at Time 2 .

The Amplifying Effect of Trait Positive Affectivity in the Culture of Companionate Love. The importance of a cultural fit between the employee's individual values and those of the larger organizational culture has been shown in the literature on cognitive culture (Chatman, 1991; O’Reilly, Chatman, and Caldwell, 1991; Chatman and Barsade, 1995), and we expect a similar process to operate for emotional culture. Specifically, we expect an important affective individual difference to moderate the main effect of a culture of companionate love we describe above: employee trait positive affectivity. Trait positive affectivity (trait PA) is a person's tendency toward having pleasant emotional engagement with, or appraisal of, his or her environment (Staw, Bell, and Clausen, 1986; Watson, Clark and Tellegen, 1988). Individuals high in trait PA are in a good mood more often and, as a result, attend to the positive aspects of their environment in ways that are congruent with that positive mood (see Bower, 1991, for a review). Therefore, we expect that employees higher in trait PA will perceive and appreciate the positive emotions enacted in a culture of love more than employees lower in trait PA. ${ }^{2}$ Reinforcing this prediction is research showing that people high in

\footnotetext{
${ }^{2}$ We focus only on trait positive affectivity (Trait PA) and not trait negative affectivity (Trait NA) because the two constructs have been found to be orthogonal (Watson, Clark and Tellegen, 1988), especially when assessed over longer time periods (Diener and Emmons, 1984); furthermore, trait PA has been consistently shown to relate to social interaction and activity (Watson et al., 1992), whereas trait NA has not, not even within work-teams (Barsade et al., 2000).
} 
trait PA make an effort to maintain a positive state (Fiske and Taylor, 1984) and to engage in "affect repair" when their positive mood is under threat (Isen, 1984).

Hypothesis 5: A culture of companionate love will have a stronger influence on the attitudes and behaviors of employees with high trait positive affectivity than on those with lower trait positive affectivity. The Cascading Effect of a Culture of Love on Patients and their Families.

Patient psychological well-being. Critical to patients' well-being in a long-term healthcare setting is their emotional relationship with the long-term care employees who care for them (Ruckdeschel and Van Haitsma, 2004). The healthcare literature describes at least two specific types of patient psychological wellbeing in the long-term care setting: the moods shown by patients on a daily basis (Lawton, Van Haitsma, and Klapper, 1996) and a multifaceted set of "quality-of-life factors," (Goodwin and Intrieri, 2006), including patient satisfaction. Displays of affection in caregiving settings have been associated with both patient pleasant mood (Tetz et al., 2006) and with quality-of-life factors (Cox et al., 1991; McGilton, 2002). Feeling mechanisms, such as emotional contagion, can underlie this effect: when patients see a nurse treating another nurse kindly at the nursing station, for example, or notice a caregiver give a warm hug to a fellow patient, the patients "catch" the employee's affection, leading to more pleasant moods (Hatfield, Cacioppo, and Rapson, 1993; Barsade, 2002). These positive emotions can also elicit a "broaden-and-build" response (Fredrickson, 1998), expanding patients' physical, intellectual, and social resources and increasing their willingness to engage in a greater variety of activities and play, all of which lead to a higher quality of life. In addition, positive feelings resulting from displays of companionate love can help people cope with negative emotional experiences, leading to greater resilience (Tugade and Fredrickson, 2004) and further enhancing quality of life. Normative enactment mechanisms such as affective social exchange can also operate, whereby patients enhance their well-being by reciprocating positive emotions shown toward them (Li, 2003).

Hypothesis 6: A stronger culture of companionate love at Time 1 will be positively associated with patient pleasant mood, quality of life and satisfaction at Time 2 .

Patient health. Besides improving patients' psychological well-being, a culture of companionate love should also have positive effects on patients' physical health. Positive affect has been associated with a 
plethora of positive health outcomes (Gil et al., 2004; see Lyubomirksy, King and Diener, 2005, for a review), including in older populations (Ong, 2010). In one study, people who reported "feeling loved" had lower levels of coronary artery disease (Seeman and Syme, 1987). A particularly interesting manifestation of this phenomenon was found in an fMRI study conducted by Coan, Schaefer, and Davidson (2006). Coan and colleagues found that having someone hold the hand of a person anticipating an electric shock had a positive effect on bodily arousal, visceral and musculoskeletal responses, emotional regulation, and stress response in the person's brain, including the affective part of pain processing. This study illustrates how enacting a culture of love-for example, through the artifact of physical touch (with and without actually feeling the companionate love)—can contribute to positive patient health outcomes.

Hypothesis 7: A stronger culture of companionate love at Time 1 will be positively associated with patient health outcomes at Time 2 .

Family satisfaction. The main factor determining a family's satisfaction with a long-term care organization is the family members' perception of how well their patient family member is being treated (Bowers, 1988; Kellett, 1999), including how the individual is being treated emotionally. Both feeling mechanisms and normative enactments of affection, caring, tenderness, and compassion could explain the influence of a culture of companionate love on family satisfaction. Families and patients cite lack of companionate love in the form of affection and caring as a source of great upset, making them "emotionally aware of being 'not wanted' " (McGilton and Boscart, 2007:2153). Thus, if families see a culture of companionate love expressed by employees, they are likely to be more satisfied with the long-term care facility.

Hypothesis 8: A stronger culture of companionate love will be positively associated with the patient's family satisfaction with the long-term care facility.

Please see Figure 1 for a summary of our theoretical model of an emotional culture of companionate love, including its specific outcomes within this long-term healthcare setting for employees, patients, and their families. 


\section{Methods}

\section{Overview of the Study}

The setting for this study was a large not-for-profit long-term healthcare facility in a major metropolitan city in the Northeastern United States. Using multiple raters and multiple methods, we measured the influence of the culture of companionate love on employee, patient, and family outcomes spanning the attitudinal, emotional, behavioral, and health domains. Because this study used a longitudinal design, we measured all predictor variables at Time 1 and all dependent variables at Time 2, 16 months later.

\section{Sample and Data Gathering Procedure}

The study sample consisted of 185 employees, 108 patients (called "residents" because they live in the facility), and 42 family members of patients. To be included in the final sample, employees, patients, and families must have taken part in the study at both Time 1 and Time 2. The data collection took place in thirteen of the organization's units distributed across the facility's three geographic sites. A unit was a separate physical area with its own set of employees and patients; the unit is the level of analysis at which we measure the culture of companionate love. The units were all closely equivalent in terms of types of patients and employees.

Employees. At Time 1, we invited all employees in the study units to take part in our study. Employees included certified nursing assistants, nurses, social workers, physicians, food service workers, and employees in at least eight other jobs on the unit. See Table 1 for a detailed description of employee characteristics. The survey, which employees completed during a paid break from their work duties, measured each the unit's culture of companionate love; it also measured employee engagement (satisfaction and teamwork) and disengagement (emotional exhaustion) within the workplace. In addition, we obtained data on a second measure of disengagement (absenteeism) directly from the organization's archival database.

287 out of 383 employees across the study units chose to participate at Time 1 - a $75 \%$ response rate.

Of those employees who participated at Time 1, 37 had left the organization by Time 2, leaving 250 employees who could participate in the study. $74 \%$ percent of those employees participated at Time 2 , yielding a final sample of 185 employees. With the exception of certified nursing assistants (CNAs), who were more likely to participate at Time 2 than other employees $\left(\chi^{2}[1,287)=3.84, p<.05\right)$, there were no differences on key 
independent and control variables described below between employees who did and did not participate at Time 2. We control for CNA status in all employee analyses.

Patients. 432 patients across the study units were eligible for the study at Time 1, of whom 199 participated in the study (a 46\% response rate). Of those patients who participated in the study at Time 1, 36 died and 26 had either been moved to another unit or were discharged from the facility before Time 2. Of the 137 patients who were available to participate in the study at Time 2, there was a $79 \%$ response rate, leading to a final sample of 108 patients. If a patient lacked the cognitive ability to give informed consent (usually because of Alzheimer's disease or other forms of dementia), the patient's primary contact or surrogate was asked to give consent for the patient's participation in the study. Although lower functioning patients were less likely to participate at Time $2\left(\chi^{2}[1,162]=7.50, p<.01\right)$, there were no other differences on independent and control variables between patients who participated at Time 2 and those who did not participate. In all patient analyses, we control for patient level of functioning, as well as level of cognitive impairment and patient health.

We gathered three types of patient data: individual attitudinal data, CNAs' ratings of patient positive mood, and health outcome data. Using interval scales read aloud to the patients in one-on-one interviews conducted by research assistants, we assessed patients' quality of life and their satisfaction with the longterm care facility. To triangulate our attitudinal findings - and because $79 \%$ of the patients were not able to communicate verbally due to Alzheimer's, dementia, or other ailments—we also examined patients' quality of life indirectly, by asking each patient's primary CNA to rate the patient's pleasant mood, as described below. Last, to obtain health data for each patient, we used the organization's medical database. See Table 1 for detailed patient characteristics.

Families of Patients. Families of the 199 patients who took part in the study at Time 1 were sent a questionnaire that contained a culture of companionate love scale, as well as questions about their attitudes toward the long-term care facility. Despite multiple mailings and follow-up calls, the response rate was only 39\% (78 families). There were no significant differences between the health, cognitive abilities, and physical functioning level of the patients whose families participated in the study and those who did not participate. Of the families who participated, 17 had family members who died and 9 had family members either transferred to another unit or discharged from the facility prior to Time 2. This yielded a possible sample of 
52 families of patients who were eligible for participation at Time 2, of whom $81 \%$ responded, leading to a final sample of 42 families. See Table 1 for detailed family characteristics.

\section{Independent Variables}

Culture of Companionate Love Scale. To operationalize a culture of companionate love, we constructed a scale derived from Shaver et al.'s (1987) prototype model of emotions. In this model, Shaver finds that the overarching prototype of love has three subcategories: affection, romantic love and longing. The first subcategory, affection, is the term Shaver et al (1987) and subsequent emotion prototype researchers (e.g., Fehr and Russell, 1991) used to represent the companionate love construct. From this subcategory, we chose emotion terms that also met the following criteria: they matched the broader literature on companionate love, they would be understood by employees, and they would have face validity in a business setting. Thus, the culture of companionate love scale consisted of the following items: affection, caring, compassion, and tenderness. ${ }^{3}$

We employed the culture of companionate love scale within the units by asking multiple types of respondents (outside raters, employees, and families) to report on the frequency of expression of companionate love shown by employees at a collective level on a scale of 1 (Never) to 5 (Very Often). This measure is broad enough to include the manifestations of culture at all three levels of abstraction (artifacts, values, and assumptions) and also incorporates the manifestations that are unique to emotional culture (facial expressions, body language, vocal tone and touch). It is also easily recognizable to outside observers, whose ratings of the units comprise our primary measure of a culture of companionate love, as well as to employees and patients' family members. We used multiple types of respondents to allow for the different perspectives held by various cultural stakeholders. An acceptable level of within-group agreement at the unit level indicates the reliability of this scale. The average $\mathrm{R}_{\mathrm{wg}}$ for the employee and family ratings of a culture of

\footnotetext{
${ }^{3}$ We intentionally refrained from using the word "love" in the scale. Given its multiple meanings and possible additional colloquial romantic connotation, we were concerned the word would be misunderstood. In addition, although Shaver et al (1987) listed "liking" as one of the words describing companionate love, the construct of companionate love has been found to differ from simply liking another person (Fehr and Russell, 1991). To verify this distinction empirically, we conducted an exploratory factor analysis with a sample of 275 employees working in a different medical setting, and found that the item "liking" indeed factored separately from the other items in our scale. (Additional information is available from the authors.) Thus, given the prior literature and our own empirical verification, we did not include "liking" in our culture of companionate love scale.
} 
companionate love at the unit level was .70, with a range of .45 to .93 .

In choosing to measure the frequency in which the emotions comprising companionate love actually occurred within the unit, we drew on the distinction between descriptive and prescriptive culture. Descriptive culture reflects what is actually occurring in an organization and has been shown to exercise powerful social control (Cialdini, 2007). Prescriptive culture, in contrast, measures aspirational values, or the “should" aspect of culture (Cialdini, et al., 1991). We chose to use a descriptive measure of the culture of companionate love because it best reflected the focus of our theorizing, which is based on the actual expression of the emotions comprising a culture of companionate love. Such expressions are primarily communicated through facial expression, body language, auditory tone and touch, and can also involve the spoken word, all of which can be reliably decoded by others (Mehrabian, 1972; Hatfield and Rapson, 2000; Hertenstein et al., 2006). ${ }^{4}$

Outside Rater Observations. Our primary measure of a culture of companionate love was outside observer ratings of the culture. We obtained this rating by employing three trained research assistants to assess a unit's culture of companionate love at multiple points in time during the Time 1 data collection. Raters were able to integrate easily and naturally into the unit while they were observing culture, since both employees and patients were accustomed to seeing them in a variety of other research capacities. After spending an average of 27 minutes (s.d.=18.28) each time they were on a unit, outside raters completed the culture of companionate love scale, responding to the question, "How frequently did employees on this unit express the following emotions?" for the time period observed. The display of emotions included all expressions of companionate love on the part of employees, both toward other employees and toward the patients who lived on the unit. Raters averaged 7.98 (s.d. $=4.10$ ) visits to each unit during the Time 1 data collection. The mean of the outside raters' ratings of the culture of love across all units was 3.35 (s.d.=.97). The reliability of ratings within units is represented by an intraclass correlation coefficient (ICC) of .73. Because each outside rater

\footnotetext{
4 There is empirical support for the focus on descriptive culture in this setting as well. In a pre-test we measured prescriptive culture consisting of "should" statements about the degree to which positive emotions should be discouraged versus encouraged on the unit, in addition to descriptive culture measures we ultimately used in the study (Cialdini et al., 1991). As employees' ratings of prescriptive norms tend to reflect aspirational values (Siehl and Martin, 1990), it was not surprising that the prescriptive ("should") norms for expressing positive had very limited variation ( $\mathrm{M}=4.86$; s.d. $=.18$, median and mode equaled 5 on a five point scale).
} 
was assigned to a different geographic site, we also verified inter-rater reliability by having all three outside raters rate a single, same unit. The result was an ICC of .71 for the three raters.

Employee Observations. Employees completed the culture of companionate love scale at the Time 1 survey administration by answering the question, "In general, how frequently do other employees in your unit express the following emotions?" with regard to affection, caring, compassion, and tenderness on the 1-5 scale $(1=$ Never through $5=$ Very Often $)($ mean $=3.97$, s.d. $=.70$, Cronbach alpha $=.73)$.

Observations from Patients' Families. Family members of patients rated culture of companionate love at Time 1 using the same scale as employees, but with a stem that asked the following question: "In general, how frequently do staff in your family member's/friend's unit express the following emotions?" (mean $=3.94$, s.d. $=.93$, Cronbach alpha $=.91)$.

Employee Trait Positive Affectivity (PA). We measured employee trait positive affectivity during the survey administration at Time 1. Because of the survey's space constraints, we used a shortened version of Watson, Clark, and Tellegen's (1988) Positive and Negative Affect Schedule (PANAS), measuring five trait positive affectivity scale items (enthusiastic, interested, alert, determined, and active) that were representative of each of the co-varying items groups in the PANAS (Crawford and Henry, 2004). The mean of this scale at Time 1 was 4.10 (s.d. $=0.64$, Cronbach alpha $=.74$ ) on a scale of 1 (slightly or not at all) to 5 (extremely).

\section{Employee Outcome Variables}

Employee Withdrawal from the Workplace. We measured employee withdrawal from the workplace at Time 2 using two variables: employee emotional exhaustion and absenteeism. To assess employee emotional exhaustion, we used the four highest factor-loading items from the emotional exhaustion subscale of the Maslach Burnout Inventory (Maslach and Jackson, 1981). Sample items include "I feel fatigued when I get up in the morning and have to face another day on the job" and "I feel used up at the end of the workday." The mean of employee emotional exhaustion was 2.86 (s.d. = 0.98) on a scale of 1 (Strongly Disagree) to 5 (Strongly Agree) (Cronbach alpha $=.82$ ).

We obtained absenteeism data from the facility's personnel records. For each employee, we took the sum of unplanned absences, including sick days, emergency holidays, and emergency vacation days for a 
randomly chosen 3-month period during the study. Over the 3-month period, mean absenteeism for employees was 3.34 days (s.d.=3.24); during this period, $85 \%$ of employees were absent at least once and, of those, the mean number of days absent was 4.24 (s.d. $=3.49$ ).

Employee Engagement with the Workplace. We measured employees' engagement with the workplace during the survey administration at Time 2 through employee teamwork and satisfaction. We measured teamwork through employees' responses to a five-item scale about how effectively employees on their units worked together as a team. Three items came from the Team Functioning Scale ("Staff on this Unit care a lot about it and work together to make it one of the best"; "As a team, this Unit shows signs of falling apart;" and "Sometimes, one of the staff members refuses to help another staff member out" - the last two reverse-coded) (Wageman, 1995). We included two additional items relevant to the construct: "My unit functions as a team" and "I can count on my co-workers for help and cooperation." On a scale ranging from 1-5 (1=Strongly Disagree through 5=Strongly Agree), the mean of the teamwork scale was 3.84 (s.d. $=0.80$, Cronbach alpha $=.81)$.

We measured employee satisfaction with a 10-item scale (Alliance Continuing Care Network of Long Term Care Facilities, 2004) commonly used in long-term care settings, including this organization. The scale addresses organizational factors that could influence employee satisfaction in a long-term care facility. It consists of items such as, "I feel valued as an employee" and "Overall I am satisfied working here," measured on a $1-5(1=$ Strongly Disagree and $5=$ Strongly Agree $)$ scale. The entire scale can be found in Appendix A. The mean of the employee satisfaction scale at Time 2 was 3.82 (s.d. $=0.80$, Cronbach alpha $=$ $.92)$.

\section{Patient Outcome Variables}

Patient Pleasant Mood as Rated by Primary Certified Nursing Assistant. Researchers have found that moods can be reliably observed in patients of long-term care facilities, even for patients with cognitive impairments such as dementia (Magai et al., 1996). Therefore, patients' primary Certified Nursing Assistants (CNAs) from the day shift— the shift in which patients spent the most time awake—rated the patients' pleasant moods at Time 2 using the Philadelphia Geriatric Center Positive and Negative Affect Rating Scale (Lawton, Van Haitsma, and Klapper, 1996). We gathered this measure of well-being-developed 
specifically for a long-term care population_-across all patients in the sample, including those who could not be interviewed because they were too frail or had Alzheimer's disease or dementia. Using these ratings also enabled us to obtain a behavioral measure for our dependent measure of patient well-being, which we could use to triangulate with our patient attitude measures.

For each patient, the CNA rater answered the following question: "Please rate the extent or duration of each affect over the past two weeks." The 1-5 scale ( $1=$ Never through $5=$ Always $)$ consisted of items such as pleasure, contentment, interest, anger, anxiety/fear, and sadness, with the negative emotions reverse-coded. The mean of patient pleasant mood was $3.84($ s.d. $=.77)$, with a Cronbach alpha of .82 .

Patient Satisfaction. We measured overall patient satisfaction at Time 2 using a 13 -item scale created for the networking alliance of long-term care facilities described above (Alliance Continuing Care Network of Long Term Care Facilities, 2004). The scale addresses organizational factors that could influence patient satisfaction in a long-term care facility. It consists of items such as "Overall, how satisfied are you with the care you receive from the nursing assistant?" and "Overall, how satisfied are you with your level of participation in the decisions about your care?" as well as a question about overall satisfaction. Patients indicated the degree to which they agreed with each statement on a scale of $1-5(1=$ Strongly Disagree and $5=$ Strongly Agree). The entire scale can be found in Appendix A. Mean patient satisfaction was 3.89 (s.d. $=0.67$, Cronbach alpha $=.88$ ).

Patient Quality of Life. We assessed patients' quality of life at Time 2 using a scale specifically designed for the long-term care population, the Quality of Life scale (Kane et al., 2003). This scale measured the following 11 components of quality of life for patients at long-term care facilities: autonomy, comfort, dignity, functional competence, food enjoyment, individuality, meaningful activity, privacy, relationships, security, and spiritual well-being. Patients indicated the degree to which they agreed with statements measuring each quality of life component on a scale of $1-4(1=$ Never through $4=$ Often $)$. To provide an overarching set of measures, we conducted a second-order factor analysis on the 11 components (see Spreitzer, 1996, for this procedure). This analysis indicated that patient quality of life could be characterized by two reliable factors: Dignity and Relationships. The first factor, Dignity, was composed of the components of dignity, autonomy, and individuality. Items included "Does staff here respect your 
modesty?" "Can you get up in the morning at the time you want?" and "Does staff here take your preferences seriously?" The mean of this scale was 3.16 (s.d. $=0.63$, Cronbach alpha $=.85)$. The second factor, Relationships, was composed of the relationships and meaningful activity components. Items included "Is it easy to make friends at this nursing home?" and "Do you enjoy the organized activities here at the nursing home?" The mean of this scale was 2.65 (s.d. $=0.67$, Cronbach alpha $=.71$ ).

Patient Health. There are myriad ways of measuring health outcomes, including cardiovascular, neuroendocrine, and immunologic function (see Seeman et al., 2002, for a review). To decide on the key indicators of patient health at Time 2, we consulted with the facility's medical leaders: the Chief of Medical Services, the medical directors from each of the three geographic sites, and the nursing directors for each of the three sites. After determining the appropriate medical measures, we verified that these variables were of management-wide interest by reviewing them with the chief administrators of the facility's three sites and with the senior management of the entire organization. Through this process, we settled on three key patient health indicators: weight gain, emergency room transfers, and pressure ulcers.

Our first indicator, weight gain, is an important marker of health because weight loss, a common phenomenon among patients in long-term care facilities, has been linked to a variety of negative outcomes_ - including infections, falls, and even death (Gambassi et al., 1999). Long-term care facilities therefore strive to have patients gain weight. We gathered weight-gain data from the organization's computerized records system for all three months immediately prior to the patient's last date of data collection. Weight gain is the difference between the final weight and the initial weight, with initial weight taken exactly three months before the final weigh-in. The weight gain ranged from -28.1 pounds (28.1 pounds lost) to 13.3 pounds (13.3 pounds gained), with a mean weight gain of -0.10 pounds $($ s.d. $=5.39)$.

Our second indicator of health is a reduction in the number of Emergency Room (ER) transfers. Inappropriate or unnecessary ER transfers are a recurring concern in the long-term care literature because such transfers are disorienting and disruptive to patients, and costly for the organization (see Jablonski et al. 2007, for a review). Using hospital transaction records, we obtained the number of transfers to the emergency room for a one-year period during the study. During this period, $29 \%$ of the patients were transferred to the emergency room at least once; of these, mean number of transfers was 1.39 (s.d. $=.70$ ). 
Our final indicator of health is reduction in the number of pressure ulcers. Pressure ulcers are an unintentional yet preventable outcome of long-term care. Because such ulcers are avoidable and can impact quality of life and mortality rates (Allman, 1997), their occurrence is often used as an indicator of poor quality of care. We obtained the incidence rate of patient ulcers from the same database used to record patient weight gain. The number of incidents ranged from 0 to 4 . While the majority of patients had no ulcers, $14.6 \%$ of patients had at least one incident of ulcers. Of these, 17 patients had Stage 1 ulcers and 12 patients had Stages 2 through 4 ulcers. The mean number of ulcer incidents was 0.25 (s.d. $=.91)$.

\section{Outcomes for Patients' Families}

Satisfaction with the Long-Term Care Facility. Family satisfaction was assessed at Time 2 using a 28-item scale measuring satisfaction with employees, patient care, hospital facilities, and hospital practices; the scale was generated by the alliance of long-term care facilities (Alliance Continuing Care Network of Long Term Care Facilities, 2004) specifically for the long-term care setting. Respondents used a 1-5 scale ( $1=$ Very Dissatisfied through $5=$ Very Satisfied $)$ to rate items including "Please let us know how satisfied you are with the performance of each of the following people your family member/friend interacts with using the scale below" (with the subsequent list including nurses, dieticians, and other facility staff), and "To what extent are you satisfied with the extent to which the physical appearance and hygiene of the patients are maintained?" See Appendix A for the full scale. The mean level of family satisfaction was 4.09 (s.d. =.80, Cronbach alpha $=$ $.92)$.

Willingness to Recommend the Long-Term Care Facility to Others. Family members were asked the following question at Time 2: "Would you recommend this facility to a friend or other family member?" on a $1-10$ scale $(1=$ Definitely No through $10=$ Definitely Yes). The mean of this measure was 8.73 (s.d. = 2.11).

\section{Control Variables}

Several individual and organizational variables not of direct interest to our study could influence outcome variables, particularly in such a rich and dynamic field setting. Therefore, we statistically accounted for Time 1 control variables before examining the influence of a culture of companionate love on outcomes at Time 2. For employee analyses, we controlled for the employee's sex, tenure at the long-term care facility, 
certified nursing assistant versus other type of employee, trait positive affectivity, and individual social desirability bias. For patient and family analyses, we controlled for three sets of factors commonly used in the gerontology literature to assess health and functioning: overall poor health, level of cognitive functioning (Morris et al., 1994), and overall physical functioning (Huang et al., 2003). We did so because being a geriatric patient in a long-term care setting can lead to complex interactions between psychosocial and health outcomes. At the unit level, we also took into account the influence of geographic site and whether the unit was part of an organizational change initiative. For more details about all the control variables, see Appendix B.

\section{Analysis}

Because our data are cross-level, consisting of observations at the individual level nested within hospital facility units, we used multi-level modeling with random effects for our analyses (Krull and MacKinnon, 1999). All outcome measures were assessed at the individual level; however, because we assessed emotional culture at both the unit level (level 2) and the individual level (level 1), we used two different types of multilevel models. Our primary independent variable was measured at the level 2 or unit level (that is, culture of companionate love measured by outside observer ratings) and, as such, we ran intercepts-as-outcome models in which the level 2 culture variable influenced the individual level (level 1) outcomes. For additional models in which all variables (that is, employee ratings of culture of companionate love and employee dependent variables) were at the individual level (level 1), we included the unit (level 2) as a random effect to control for additional sources of level-2 variance. We employed SAS "PROC MIXED” and "PROC GLIMMIX" (Littell et al., 2002) to examine hypotheses pertaining to normally distributed and non-normally distributed (or count) variables, respectively. The model for each variable produced a fixed coefficient $(\gamma)$ while controlling for individual- and unit-level sources of variation. All non-categorical variables were grandmean-centered (Hofmann and Gavin, 1998). Following Aiken and West (1991), we centered all interaction terms. For each model, we estimated the pseudo $R^{2}$ values by calculating the proportional reduction in 
variance in mean squared prediction error between the null models and the fitted models (Snijders and Bosker, 2011).

\section{Results}

We report inter-correlations among variables used in the analyses in Table $2 \mathrm{a}$ (employees), Table $2 \mathrm{~b}$ (patients), and Table 2c (families of patients). To assess the relationships among the multiple measures of the culture of companionate love, we examined inter-correlations among the three sets of culture of companionate love ratings (outside raters, employees, and family members) at the unit level of analysis. The correlations between outside raters and employee ratings and between outside raters and family ratings were $.39(\mathrm{p}<.10)$ and $r=.52(\mathrm{p}<.05)$, respectively. The correlation between employee and family ratings was not significant at $r=.05$.

\section{Employee Outcomes.}

To test whether the culture of companionate love was associated with employee outcomes, we first examined the outside raters' observations of the culture of companionate love at Time 1 as the independent variable predicting employee outcomes at Time 2, 16 months later. As shown in Table 3, and supporting Hypotheses 1, 2, 3, and 4, a stronger culture of companionate love at Time 1 as rated by outside observers was associated with the following outcomes at Time 2: lower employee emotional exhaustion $(\gamma=-.40, p<$ $.05)$, less absenteeism $(\gamma=-.21, p<.05)$, greater employee teamwork $(\gamma=.56, p<.05)$, and higher employee satisfaction $(\gamma=.51, p<.01)$.

As shown in Table 4, employees' ratings of culture of companionate love at Time 1 did not have the predicted main effect on employee emotional exhaustion at Time $2(\gamma=-.07$, n.s.), offering no additional support for Hypothesis 1. However, employee ratings of a culture of companionate love at Time 1 were significantly and negatively related to Time 2 employee absenteeism $(\gamma=-.14, \mathrm{p}<.05)$, and were significantly and positively associated with better teamwork $(\gamma=.29, \mathrm{p}<.001)$ and greater employee work satisfaction $(\gamma=.27, \mathrm{p}<.001)$ at Time 2, offering additional support for Hypotheses 2, 3, and 4 . 
Hypothesis 5, which predicted that employees high in Trait PA would have their attitudinal and behavioral outcomes more strongly influenced by a stronger culture of companionate love than would employees low in Trait PA, was largely supported. As reported in Table 4, the interaction of trait PA and employee ratings of culture of companionate love was significantly related to employee emotional exhaustion $(\gamma=-.30, \mathrm{p}<.05)$, teamwork $(\gamma=.25, \mathrm{p}<.05)$ and satisfaction $(\gamma=.41, \mathrm{p}<.001)$, although not to absenteeism $(\gamma=.08$, n.s.). To further examine the interaction effect, we plotted the culture of companionate love and trait PA to create the interaction term. Figures $2-4$ plot the relevant employee outcomes for employees at one standard deviation above the mean for trait PA (high trait PA), mean levels of trait positive affectivity (average trait PA), and one standard deviation below the mean for trait PA (low trait PA). As shown in figures 2-4, and in support of Hypothesis 5, there was a linear relationship between trait PA levels and the degree to which employees were influenced by a culture of companionate love. As predicted, employees with higher trait positive affectivity were more strongly influenced by the culture of companionate love than employees lower in trait positive affectivity across the variables of teamwork, satisfaction and emotional exhaustion, but not absenteeism.

\section{Patient Outcomes.}

Outside observer ratings of the culture of companionate love on the unit at Time 1 were also used to test Hypothesis 6, the influence of a culture of companionate love on patient mood, quality of life, and satisfaction at Time 2. We first examined whether a stronger culture of companionate love would be positively related to patient pleasant mood at Time 2, with pleasant mood rated by a patient's primary daytime CNA. As shown in Table 5, we found support for this outcome within Hypothesis $6(\gamma=.46, \mathrm{p}<$ .05) ${ }^{5}$ Hypothesis 6 also predicted that a stronger culture of love would be positively related to patient satisfaction and quality of life. Using the sample of patients who were able to communicate verbally, we found support for this hypothesis, as well. As shown in Table 6, there was a positive and significant association between a culture of companionate love at Time 1 as measured by outside raters and patient

\footnotetext{
${ }^{5}$ To control for any bias in the patients' primary Certified Nursing Assistants' (CNAs) ratings of patients' moods, we included the trait positive affect and social desirability of patients' primary caretakers (which we also control for in all employee analyses) in the multilevel model predicting patient pleasant mood. When controlling for all patient control variables and these CNA control variables simultaneously, the influence of the culture of companionate love on patient mood remained statistically significant.
} 
satisfaction $(\gamma=.60, \mathrm{p}<.01)$, patient quality of life measured in terms of dignity $(\gamma=.75, \mathrm{p}<.05)$, and patient quality of life in terms of relationships $(\gamma=.57, \mathrm{p}<.05)$ at Time 2.

We also examined whether a stronger culture of companionate love would relate to positive patient health outcomes. As shown in Table 7, hypothesis 7 was only partially supported, with Time 1 culture of companionate love measured by outside observer ratings having a significant association with Time 2 trips to the emergency room $(\gamma=1.61, \mathrm{p}<.05)$, but no significant relationship to Time 2 patient weight gain $(\gamma$ $=.57$, n.s.) or lower incidence of ulcers $(\gamma=.20$, n.s.).

\section{Family Outcomes.}

Last, we tested whether a stronger culture of companionate love would predict patients' families' outcomes. Because a patient's health and cognitive condition could influence family perceptions of the facility, in all our analyses we controlled for Time 2 patient poor health, cognitive impairment, and poor physical functioning. As shown in Table 8, a stronger Time 1 culture of companionate love (as rated by outside raters) was not significantly related to greater family member satisfaction $(\gamma=.32$, n.s.) or a greater willingness to recommend the long-term care facility to others $(\gamma=.29$, n.s. $)$ at Time 2 . However, as seen in Table 9, families' own ratings of the culture of companionate love at Time 1 did have a positive and significant association with family member satisfaction $(\gamma=.41, \mathrm{p}<.001)$ and a willingness to recommend the long-term care facility to others $(\gamma=.49, \mathrm{p}<.001)$ at Time 2 , offering partial support for Hypothesis 8 .

\section{Exploratory Analyses: Cultural Artifacts of a Culture of Companionate Love}

As an exploratory analysis, we measured some indications of the influence of a culture of companionate love measured through cultural artifacts. Although cultural artifacts are a prototypical manifestation of organizational culture that is visible to both outsiders and insiders alike, it has not been common to measure cultural artifacts in quantitative examinations of culture. We do so here in an exploratory fashion to obtain a broader understanding of the culture of companionate love. We specifically focused on cultural artifacts that, based upon our on-site observations, as well as on prior research (Langer and Rodin, 1976), were consistent with a culture of companionate love in a long-term care organization. Companionate love for patients, families, and staff in this setting centers around artifacts that create a sense of 'homeliness', a concept that reflects warm memories, loving ties with family and friends, and feelings of autonomy (Rigby, Payne, and Frogatt, 2010). 
Indoor plants (Cohen-Mansfield \& Werner, 1998) and personalized patient rooms (such as individually chosen furniture, bedspreads, and knickknacks) (Kellehear, Pugh, and Atter, 2009) are common exemplars of this concept in the long-term literature. Artifacts that detract from an "institutionalized" look - such as colorful tablecloths in the dining room (Hotaling, 1990) - are another common example of companionate love artifacts in this setting. Thus, we chose the following artifacts: plants in the common areas, plants in the patients' rooms, tablecloths in patient dining areas, centerpieces on the tables, and personalized patient rooms (such as individually chosen furniture, bedspreads, and knickknacks). We created a scale of the existence of each of these artifacts on the unit. For each unit the scale was completed by a head nurse and 2 or 3 administrators directly related to human resources and culture on the unit (mean number of coders $=3.54$, s.d. $=.52$ ). We asked employees on both the day and evening shifts to complete the scale. For each item, coders responded to the question, "How often are the following found on the unit?" on a $1-5$ scale $(1=$ Never through $5=$ Very often; mean $=3.70$, s.d. $=.79$, Cronbach alpha $=.82$ ).

Examination of the intercorrelations between culture of companionate love artifacts and the three other measures of culture of companionate love revealed a high degree of overlap. Specifically, culture of companionate love as measured through cultural artifacts was correlated $r=.60(\mathrm{p}<.05)$ with outside rater observations, $r=.42(\mathrm{p}<.10)$ with employee ratings, $r=.51(\mathrm{p}<.05)$ with family member ratings of a culture of companionate love. As shown in Table 10, we found significant results for all employee outcomes when culture of companionate love was measured through cultural artifacts. Specifically, the culture of companionate love as manifested through cultural artifacts at Time 1 predicted less employee emotional exhaustion $(\gamma=-.48, p<.001)$ and lower absenteeism $(\gamma=-.38, p<.01)$, better teamwork $(\gamma=.55, p<$ $.001)$, and greater employee work satisfaction $(\gamma=.44, p<.001)$ at Time 2 . However, there were no significant relationships for the culture of companionate love as measured through cultural artifacts on patient or family outcomes at Time 2 .

\section{Discussion}

We draw on a variety of scholarly perspectives to build a theory of a culture of companionate love and test its importance in a longitudinal study of employees and their clients in a long-term care setting. By demonstrating how a culture of companionate love manifests itself at work, we show that companionate 
love_-a basic human emotion with deep academic roots—does not stop at the organizational door, but, rather, has an important influence on what happens within, for both employees and clients alike. Across multiple measures of the culture of companionate love - outside observer ratings, employees' own ratings, family ratings and the presence of cultural artifacts - we found that a stronger culture of love at Time 1 was almost always negatively associated with employee withdrawal and positively associated with employee engagement at Time 2, 16 months later. Echoing findings from the culture-fit literature, we found that trait positive affectivity moderated the effect of employees' ratings of a culture of love on employee outcomes. A culture of companionate love had a greater reduction in emotional exhaustion (though with no influence on absenteeism) and a stronger positive influence on the satisfaction and teamwork of employees who were higher rather than lower in trait positive affectivity.

We also extended our examination of a culture of companionate love to the organization's clients, the patients and their families. Outside observers' ratings of the culture of love at Time 1 positively related to more positive patient pleasant mood (as rated by the patients' primary certified nursing assistants—even after controlling for the CNAs' own individual characteristics), greater patient satisfaction, and higher quality of life at Time 2. We found a relationship between a culture of companionate love at Time 1 and fewer trips to the emergency room, only one of the three health outcomes we investigated at Time 2 . However, given the growing literature positing a relationship between positive emotions and physiological outcomes (Heaphy and Dutton, 2008; Ong, 2010), the relationship between a culture of companionate love and patient health deserves future research, including the search for moderators and mediators that may better explicate the relationship. Last, we found that families' own ratings of a culture of love at Time 1 (although not outside raters' observations) related to family satisfaction and willingness to recommend the facility to others at Time 2.

In general, the robustness of our findings speaks to the pervasiveness and intensity of a culture of companionate love on employees and their clients. However, some results that were not significant warrant further consideration. For example, the lack of significant effects for outside raters' observations of culture on family attitudes could be due to the comparatively small number of families who participated or the fact that families have a more limited vantage point from which to observe the emotional culture of units in a 
long-term care facility. In addition, in our exploratory analyses, cultural artifacts showed a strong relationship to employee outcomes, but were not associated with patient or family outcomes. These puzzling findings raise intriguing questions_-still largely unexplored within the organizational culture literature-about the relationships among different manifestations of culture (Hatch, 1993). Although three of the four sets of culture of companionate love ratings were significantly correlated with one another, the magnitude of the associations among raters varied, with employee ratings of culture being least significantly correlated with the other three measures. Some organizational culture scholars promote the notion that subgroups have different vantage points on culture, which may or may not be in agreement, particularly in medical settings (Meyerson, 1994). It may also be that, as varied theorists have suggested (Schein, 2010; Trice and Beyer, 1993; Hall et al., 1997), different levels of culture have varying degrees of influence on cultural constituencies, all of whom observe different components of culture.

\section{Major Theoretical Contributions}

Our study revives the largely dormant investigation of companionate love at work. Although social scientists have made promising qualitative inquiries, quantitative examinations of the construct of love at work by contemporary organizational theorists have been largely absent. Even within psychology, the field that has studied companionate love most closely, scholars have been limited in the domains in which they examine this construct, and have explicitly called for more research on the construct in broader contexts (Reis and Aron, 2008). Thus, by focusing on the influence of companionate love on workplace outcomes, our study fills research gaps in both organizational behavior and psychology. Our findings challenge contemporary assumptions about companionate love in the workplace, specifically the assumption that workplace relationships cannot be deep enough to be defined by "love" or that love is not important for organizational outcomes. Not only do we find that employees' experiences within a culture of companionate love significantly relate to their level of workplace engagement and withdrawal, but we also discover that the consequences of a culture of love ripple out to patients— this organization's clients_-and even to clients' families.

In examining the culture of companionate love in organizations, we also hope to contribute to the positive organizational scholarship literature, particularly the burgeoning study of compassion organizing 
(Kahn, 1993; Kanov et al., 2004; Dutton et al., 2006). While the compassion organizing research touches a broad swath of constructs (e.g., Rynes et al., 2012), thereby differentiating it from the purely affective approach we adopted in the present study, it remains one of the only areas within organizational behavior research that has explicitly focused on the importance of deep and compassionate relationships among employees. We have drawn on compassion research in our theorizing about the broader construct of a culture of companionate love, and have also made unique contributions to this domain of research as well. From a theoretical perspective, the construct of a culture of companionate love offers a broader lens that highlights the myriad aspects in which employees can have deep and meaningful relationships at work. We view this explicitly culture-level approach to companionate love as an important and novel lens on organizational compassion and compassion organizing research. Our research also adds a useful quantitative component to this area, which to date has focused almost exclusively on theoretical articles and qualitative case studies.

Of equal importance to the revival of the study of companionate love at work is our contribution to the literature on organizational culture. By showing the existence and relevance of companionate love as collective, cultural construct, our study contributes to a research area that is critical to organizational life, but which was in need of reinvigoration. After the "culture wars" of the 1990s (Denison, 1996), there have been few new perspectives or paradigms offered within organizational culture research. By studying the construct of a culture of companionate love specifically, and the idea of emotional culture more generally, we introduce a novel and more complete approach to understanding organizational culture and its consequences, establishing a baseline for future research. Our theorizing departs from and expands on traditional cognitive organizational culture research in two major ways. First, our focus is upon the cultural manifestations of deep underlying assumptions, values, norms and artifacts based exclusively on the emotional content of culture. By providing a rich portrait of what emotional culture crystallization and intensity look like through the lens of companionate love, we extend early work on the concept of culture strength by sociologists (Jackson, 1966) to the domain of emotional culture. The dimensional approach to conceptualizing culture was a critical advance for cognitive research culture in the 1990's (e.g., O'Reilly et al., 1991) that can also shape future research on emotional culture. For instance, increasing our ability to 
precisely examine the dimensions of emotional culture can enhance our ability to separate out the various possible emotional culture constructs. Second, a major difference between cognitive and emotional culture is that emotional culture is enacted and transmitted mainly through nonverbal and physiological channels. One implication of this insight is that emotional culture will spread among employees via both feeling mechanisms as well as normative enactments. As the concept of feeling mechanisms is new to the culture literature, future studies of emotional culture will need to focus on human experience of emotions and the ways in which they are uniquely transmitted through facial expression, body language, vocal tone and touch as the core defining feature of the emotional culture construct. Thus, emotional culture offers a new perspective on the organizational culture construct, and offers a generative new area of inquiry within this domain.

\section{Is a Culture of Companionate Love Important in Other Industries?}

A natural question arising from our study of companionate love in the long-term care industry is whether the implications of these findings are also relevant for managers in other industries. Although the long-term care industry nicely illuminates the relationship between a culture of companionate love and employee and client outcomes (see discussion of theoretical sampling; Eisenhardt and Graebner, 2007), our approach runs the risk of being less representative of other business organizations. While we have offered examples and theoretical support for employees showing affection, caring, compassion, and tenderness in other industries, to approach the question more systematically, we conducted an illustrative examination of the culture of companionate love among 3,201 employees spanning seven different industries (Biopharmaceutical, Engineering, Financial Services, Higher Education, Real Estate, Travel, and Utilities).

Using the same employee culture of companionate love scale we used in this study, we found that employees' ratings of the culture of companionate love were significantly positively correlated with one-item measures of job satisfaction $(r=.23, p<.001)$, commitment to the organization $(r=.21, p<.001)$, and accountability for work performance $(r=.07, p<.01)$. Interestingly, this sample also showed that although there were significant differences in the culture of companionate love between industries $(F=25.4, p<.001)$, industry differences did not fully account for the strength of culture of love. Rather, the strength of culture of love differed significantly even within a single industry. For example, there were significant differences in 
the culture of companionate love within a sub-sample of 332 employees in four different firms in the financial services industry $(F=5.39, p<.001)$, with means ranging from 2.71 to $3.35(\mathrm{M}=3.06$, s.d. $=.68)-$ as high as observer ratings of a culture of companionate love that we found in the long-term care industry. Although this cross-sectional sample is not a definitive test, it does suggest that the level of an organization's culture of companionate love is related to employee engagement across a variety of organizations and industries.

\section{Is Emotional Culture Relevant to Other Emotions?}

Through our focus on a theory of an emotional culture of companionate love, we hope to also spark more research into other types of emotional culture. Just as culture of companionate love played an important role in a long-term care setting, it seems likely that cultures defined by other discrete emotions can be functional in other types of organizations. For example, whereas the other-centered emotion of companionate love proved beneficial in a caregiving setting, it may be that more "ego-focused" emotions, such as enthusiasm and pride (Kitayama, Markus, and Kurokawa, 2000), would be more adaptive in work that focuses more on individual achievement, such as sales or investment banking. It is also important to note that the same emotional culture might lead to very differing outcomes depending on other organizational factors. For example, whereas a culture of fear could promote safety-oriented behaviors among employees in one type of organization, such as a governmental security agency or fire-fighters, the same culture of fear would likely have devastating consequences for organizations that thrive on the free flow of ideas, such as design and engineering organizations like IDEO. Also, emotions generally classified as negative can have constructive effects; Intel, for example, with its ritual of "constructive confrontation," fostered aspects of a culture of anger and found it to be helpful for improving employee performance (Jackson, 1998).

Within long-term care or other health care settings, it would be interesting to examine whether a culture of companionate love relates to other types of emotional cultures, such as a culture of sadness. Given that death and dying are inherent to work in a long-term care setting, emotions such as sadness and grief could be an acceptable and expected part of the culture in a way that is not acceptable in other types of organizations. Across industries, the relationship between a culture of companionate love and a culture of 
anger is also intriguing. While one could intuitively posit that these two types of emotional cultures would be inversely correlated, they may also be positively correlated since anger, too, often emerges in the context of interpersonal relationships (Gibson and Callister, 2010). For example, employees in a strong culture of companionate love are very focused on their relationships with each other, which could extend to an acceptability regarding the expression of anger when relationships are threatened or group norms are violated. The closeness that the culture of love brings may also create a psychologically safe environment for employees bonding together through anger over unpleasant work conditions.

Investigation of additional moderators of emotional culture is another promising avenue of research. Just as trait positive affectivity enhanced the effects of the culture of companionate love in our study, other individual differences, such as emotional intelligence (Mayer, Salovey, and Caruso, 2000), emotional regulation style (Gross and John, 2003), propensity toward emotional contagion (Doherty, 1997), otheroriented versus self-image interpersonal goals (Canevello and Crocker, 2010), or Big-5 personality traits (Barrick and Mount, 1991) could also moderate emotional culture's effects, depending on the type of emotional culture. Last, although the structure of our model and the two main mechanisms through which we predict it will influence outcomes are generalizable to other emotional cultures, the particulars will likely vary by emotional culture. Therefore, middle-range theory (Merton, 1968) will be necessary to explain how and what types of outcomes will result from each particular type of emotional culture.

\section{Can There Be Too Much of a Culture of Companionate Love?}

An emotional culture that is built around particular discrete emotions which are adaptive for the group in most contexts may not always lead to positive outcomes or be suitable in all situations. For example, in a culture of companionate love, it is possible that employees who are too affectionate, caring, compassionate, and tender with one another might be more likely to ignore unethical behavior on the part of their co-workers because they do not want to jeopardize their co-workers' jobs. Indeed, one theory of bureaucracy holds that bureaucracies" "formalistic impersonality" stems from the belief that compassion undermines fairness (du Gay, 2008, p.350). Clark (1997), for instance, describes how physicians at a group medical practice were willing to forgive their colleague's accounting fraud scandal because their compassion for their colleagues was so strong following a natural disaster that struck his home. 


\section{What is the Relationship between Emotional Culture and Cognitive Culture?}

While we have predominately focused on the factors that differentiate emotional culture and cognitive culture, an interesting question for future research is: what type of relationships might exist between the two constructs? One possibility is that the various configurations of cognitive and emotional cultures are orthogonal to one another. Consider, for instance, the cultural contrast that emerges from two organizations, both of which subscribe to a results-oriented cognitive culture, but which have distinct emotional cultures stemming from their differentiated strategic orientation and the distinct personalities of their organizational leaders. The contrast between Southwest Airlines and American Airlines is one such example. While both organizations subscribe to an outcome-oriented cognitive culture (that is, achievementoriented and results-oriented; O'Reilly, Chatman, and Caldwell, 1991), there is a clear contrast between the emotional cultures of each company. Whereas employees at Southwest Airlines are encouraged to express authentic emotions, particularly love (Blanchard and Barrett, 2011), American Airlines has been called the 'stainless steel' airline, a term that reflects the emotional restraint required of its employees (Lorsch, Loveman, and Horn, 1990). It may be the case, however, that emotional and cognitive cultures can complement each other, leading to mutually reinforcing outcomes. For example, given the relationship between positive affectivity and creativity (Amabile et al., 2005), a culture of innovation is likely to get much more of a boost if there is also a culture of joy in place to bolster it. Nevertheless, it is important for future research to investigate the relationship between the two and the ways in which that relationship will collectively influence those outcomes, including an understanding of the interactions within and between them.

\section{Study Limitations}

Establishing the link between a culture of companionate love and employee, patient, and family outcomes in the long-term care industry is an important first step in demonstrating the importance of emotional culture for organizational functioning. While a strength of this study is the use of multiple-source and multi-method data collected sixteen months apart, a limitation of this design is its use of multiple units within only one organization in the long-term care industry. Future researchers should broaden both the industry and type of discrete emotional culture examined. 
It is also reasonable to question how the sex composition of our sample influenced our findings. The majority of our respondents were female, as is typical for care-related professions, including long-term care (Stone, 2000). This sex composition might have influenced our results through either feeling or normative mechanisms, particularly given previous research showing that there are differences between men and women in emotional expression, regulation and susceptibility to emotional contagion (see McRae et al., 2008, for example). On the other hand, there is evidence that men and women hold a similar conception of companionate love (Fehr and Broughton, 2001). Empirically, we conducted additional statistical analyses and found only one instance of a moderating influence of sex, and no direct influence of employee sex on either employee or client outcomes. In addition, the illustrative analysis we conducted across seven different industries consisted of $78 \%$ men, yet found a relationship between a culture of companionate love and employee attitudes in that analysis, as well. Therefore, although we should be aware of the implications of gender in organizational research, there is support that our results are generalizable to both sexes.

\section{Managerial Implications of a Culture of Companionate Love in Healthcare and Beyond}

Our first set of managerial implications relates to healthcare, the field in which we tested our hypotheses. Healthcare workers display some of the highest levels of employee dissatisfaction (Aiken et al., 2001), with staffing shortages and turnover rates ranging from $48 \%$ for nurses to as high as $119 \%$ for

Certified Nursing Assistants (Castle, 2006). Because dissatisfaction and turnover lower the quality of patient care (Castle, Engberg, and Men, 2007), creating a stronger culture of companionate love could be particularly useful in this industry (Farrell, 2001). Our finding that a culture of love is associated with more pleasant patient mood is also particularly significant for patient care, since depressive symptoms are common among patients in long-term care facilities, with estimates ranging from approximately $15 \%$ for major depression to as high as $45 \%$ for both major and minor depression (see Teresi et al., 2001, for a review). The health care industry also offers an intriguing setting to compare the influence of organizations focused on cultivating a culture of companionate love as a way to gain better employee and patient outcomes, as compared to an approach based mainly on increasing resources and staffing as a way to attain better outcomes. While it is difficult to quantify the meaning of medical care spending, this could be an important direction in healthcare research and reform. 
In addition to the importance of a culture of companionate love for healthcare, organizational leaders across industries are recognizing the value of fostering companionate love as a collective, cultural phenomenon within groups of employees and in the organization as a whole. In addition to the well- known example of Southwest airlines, other companies include Whole Foods Market, which has a set of management principles that begin with "Love" (Hamel and Breen, 2007) and PepsiCo, which lists "caring" as its first guiding principle (PepsiCo website, 2012). Zappos also explicitly focuses on caring as part of its values: "We are more than a team though...we are a family. We watch out for each other, care for each other and go above and beyond for each other" (Zappos, 2013). Given that successfully interacting with others is critical to work success, our findings provide evidence that these leaders are going in the correct direction for developing more engaged employees and clients.

For decades, management scholars have encouraged leaders to take ownership of their cognitive culture. Similarly, leaders would do well to think about and take ownership of emotional culture. A natural question is: how should leaders do so? Leader behavior is generally one of the most important transmitters of cognitive culture (Schein, 2010), and we posit that leaders are one of the most important transmitters of emotional culture as well. This influence could occur through feeling mechanisms such as emotional contagion of leader emotions, which have been shown to be particularly strong among followers (Johnson, 2008) and could be a powerful force behind the group's emotional culture.

\section{Conclusion}

By focusing on affection, caring, compassion, and tenderness in the workplace, we aim to contribute to an understanding of the culture of companionate love, and emotional culture more generally, and to highlight its importance for organizational theorists and managers alike. Classic inductive studies in the management domain recorded the importance of companionate love for employees and their supervisors, yet the importance of companionate love in modern organizational behavior theory has been systematically overlooked and the theoretical pathways linking emotions and organizational culture were not illuminated. We do so now through a longitudinal study of the culture of companionate love in the long-term care industry. We provide systematic, quantitative, multi-rater, and multi-method evidence for the link between a culture of companionate love and both employee and client outcomes. Our research confirms that 
employees can, indeed, experience love at work and reveals that a culture of companionate love relates to important employee and client outcomes. In response to Tina Turner's famously haunting lyrics, love, actually, has very much to do with it.

\section{References}

Aiken, L.H., and S.G. West,

1991 Multiple Regression: Testing and Interpreting Interactions. Newbury Park, CA: Sage.

Aiken, L. H., S. P. Clarke, D. M. Sloane, J. A. Sochalski, R. Busse, H. Clarke, P. Giovannetti, J. Hunt, A.M. Rafferty, and J. Shamian

2001 “Nurses' Reports on Hospital Care in Five Countries.” Health Affairs, 20: 43-53

Alliance Continuing Care Network of Long Term Care Facilities.

2004 "Staff, Resident and Family Satisfaction Survey."

Allman, R. M.

1997 "Pressure ulcer prevalence, incidence, risk factors, and impacts." Clinics in Geriatric Medicine, 13: 421-436.

Amabile, T. M., S. G. Barsade, J. S. Mueller, and B. M. Staw

2005 "Affect and creativity at work." Administrative Science Quarterly, 50: 367-403.

Asch, S.

1955 "Opinions and social pressure." Scientific American, 193: 31-35.

Ashforth, B.E., and R.H. Humphrey

1993 "Emotion labor in service roles: The influence of identity." Academy of Management Review, 18: 88-115.

Ashkanasy, N.M., C. P. M. Wilderom, and M. F. Peterson. (Eds.)

2011 The Handbook of Organizational Culture and Climate (2nd Ed). Thousand Oaks, CA: Sage.

Barrick, M. R., and M. K. Mount

1991 "The Big Five personality dimensions and job performance: A meta-analysis." Personnel Psychology, 44: 1-26.

Barsade, S. G.

2002 “The ripple effect, emotional contagion within groups.” Administrative Science Quarterly, 47: 644675.

Barsade, S. G., A. P. Brief, and S. E. Spataro 
2003 “The Affective Revolution in Organizational Behavior: The Emergence of a Paradigm.” In J. Greenberg (ed.), Organizational Behavior: The State of the Science (2 ${ }^{\text {nd }}$ ed): 3-52. Mahwah, NJ and London: Lawrence Erlbaum Associates.

Barsade, S. G., and D. E. Gibson

2007 "Why does affect matter in organizations?” Academy of Management Perspectives, 21: 36-59.

Barsade, S. G., A. J. Ward, J. D. F. Turner, and J. A. Sonnenfeld

2000 "To Your Heart's Content: A Model of Affective Diversity in Top Management Teams." Administrative Science Quarterly, 45: 802-836.

Bartolomé, F.

1972 “Executives as Human Beings.” Harvard Business Review, 50: 62-69.

Baumeister, R. F., and M. R. Leary

1995 "The need to belong: Desire for interpersonal attachments as a fundamental human motivation." Psychological Bulletin, 117: 497-529.

Bechky, B. A.

2003 "Object Lessons: Workplace Artifacts as Representations of Occupational Jurisdiction." American Journal of Sociology 109(3): 720-752.

Berscheid, E., and E. Walster

1974 “A little bit about love.” In T. L. Huston (ed.), Foundations of Interpersonal Attraction: 355-381. New York: Academic.

Berscheid, E., and E. Walster

1978 Interpersonal Attraction ( $2^{\text {nd }}$ Edition). Reading, MA: Addison Wesley.

Blanchard, K, and C. Barrett

2011 Lead with LUV. Upper Saddle River, New Jersey: FT Press.

Bower, G. H.

1991 "Mood congruity of social judgments." In J. P. Forgas (ed.), Emotion and Social Judgments: 31-53. New York: Pergamon Press.

Bowers, B. J.

1988 "Family perceptions of care in a nursing home." The Gerontologist, 28: 361-368.

Boyatzis, R. E., M. L. Smith, and N. Blaize

2006 "Developing sustainable leaders through coaching and compassion." Academy of Management Learning and Education, 5: 8-24.

Bridgewater website

2012 "Bridgewater." http://www.bwater.com/home/our-company/company.aspx.

Brief, A. P., and H. M. Weiss

2002 “Organizational Behavior: Affect in the Workplace." Annual Review of Psychology, 53: 279-307. 
Brotheridge, C.M., and A.A. Grandey

2002 "Emotional labor and burnout: Comparing two perspectives of 'People work'." Journal of Vocational Behavior, 60: 17-39.

Canevello, A. and J. Crocker

2010 "Creating good relationships: Responsiveness, Relationship quality, and interpersonal goals." Journal of Personality and Social Psychology, 99: 78-106.

Castle, N. G.

2006 "Measuring staff turnover in nursing homes." The Gerontologist, 46:210-219.

Castle, N. G., J. Engberg, and A. Men

2007 "Nursing home staff turnover: Impact on nursing home compare quality measures." The Gerontologist, 47: 650-661.

Chapman, B.

2013 "How a Family Shared a Burden." April, http://www.trulyhumanleadership.com/?p=645.

Chatman, J. A.

1991 "Matching People and Organizations: Selection and Socialization in Public Accounting Firms." Administrative Science Quarterly, 36: 459-484.

Chatman, J. A., and S.G. Barsade

1995 "Personality, organizational culture and cooperation: Evidence from a business simulation." Administrative Science Quarterly, 40: 423-443.

Cherniss, C.

1980 Professional Burnout in Human Service Organizations. New York, NY: Praeger.

Cialdini, R. B.

2007 "Descriptive social norms as underappreciated sources of social control." Psychometrika, 72: 263268.

Cialdini, R. B., Kallgren, C. A., and R. R. Reno

1991 "A focus theory of normative conduct: A theoretical refinement and reevaluation of the role of norms in human behavior.” In M. Zanna (ed.), Advances in experimental social psychology (Vol. 24): 201-234. New York: Academic Press.

Clark, C.

1997 Misery and Company: Sympathy in Everyday Life. Chicago, IL: University of Chicago Press.

CMS.gov website

2009 https://www.cms.gov/Medicare/Quality-Initiatives-Patient-AssessmentInstruments/NursingHomeQualityInits/NHQIMDS30.html.

Coan, J. A., H. S. Schaefer, and R. J. Davidson

2006 "Lending a Hand Social Regulation of the Neural Response to Threat." Psychological Science 17(12): 1032-1039. 
Cohen-Mansfield, J., and P. Werner

1998 "The effects of an enhanced environment on nursing home residents who pace." The Gerontologist, 38(2), 199-208.

Coté, S., and L. M. Morgan

2002 "A longitudinal analysis of the association between emotion regulation, job satisfaction and intentions to quit.” Journal of Organizational Behavior, 23: 947-962.

Cox, C. L., L. Kaeser, C. A. Montgomery, and L. H. Marion

1991 "Quality of life nursing care. An experimental trial in long term care." Journal of Gerontologic Nursing, 17: 6-11.

Crawford, J.R., and J.D. Henry

2004 "The Positive and Negative Affect Schedule (PANAS): Construct validity, measurement properties and normative data in a large non-clinical sample." British Journal of Clinical Psychology, 43: 245265.

Crowne, D. P., and D. Marlow

1960 "A new scale of social desirability independent of psychopathology." Journal of Consulting Psychology, 24: 349-354.

Decker, F. H., P. Gruhn, L. Matthews-Martin, K. J. Dollard, A. M. Tucker, and L. Bizette

2003 Results of the 2002 AHCA Survey of Nursing Staff Vacancy and Turnover in Nursing Homes. Washington, DC: American Health Care Association.

Denison, D. R.

1996 "What is the difference between organizational culture and organizational climate? A native's point of view on a decade of paradigm wars". Academy of Management review, 21: 619-654.

Diefendorff, J.M. and E.M. Richard

2006 "Are emotional display rules formal job requirements? Examination of employee and supervisor perceptions.” Journal of Occupational \& Organizational Psychology, 79: 273-298.

Diener, E., and R.A. Emmons

1984 "The independence of positive and negative affect." Journal of Personality and Social Psychology, 47:1105-1117.

Doherty, R. W.

1997 "The Emotional Contagion scale: A measure of individual differences." Journal of Nonverbal Behavior, 21: 131-154.

du Gay, P.

2008. "Without affection or enthusiasm' problems of involvement and attachment in "responsive" public management." Organization, 15, 335-353.

Durkheim, E.

[1912] 1965 The Elementary Forms of the Religious Life., translated by J. W. Swain. New York, NY: Free Press. 
Dutton, J. E., Worline, M. C., Frost, P. J., and J. Lilius

2006 "Explaining compassion organizing." Administrative Science Quarterly, 51: 59-96.

Eisenhardt, K. M., and M. E. Graebner

2007 “Theory building from cases: Opportunities and challenges.” Academy of Management Journal, 50: 25-32.

Ekman, P.

1973 Darwin and Facial Expression; A Century of Research in Review. New York, NY: Academic Press.

Elfenbein, H. A.

2007 "Emotion in organizations: A review and theoretical integration." Academy of Management Annals, 1: 371-457.

Farrell, G.A.

2001 “From tall poppies to squashed weeds: Why don't nurses pull together more? Journal of Advanced Nursing, 35: 26-33.

Fehr, B.

1988 "Prototype analysis of the concepts of love and commitment." Journal of Personality and Social Psychology, 55: 557-579.

Fehr, B. and R. Broughton

2001 "Gender and personality differences in conceptions of love: An interpersonal theory analysis." Personal Relationships, 8: 115-136.

Fehr, B., and J. A. Russell

1991 "The concept of love viewed from a prototype perspective." Journal of Personality and Social Psychology, 60: 425-438.

Fineman, S.

2000 Emotion in organizations. Sage.

Fiske, S. T., and S. E. Taylor

1984 Social Cognition (1st ed.). Reading, MA: Addison-Wesley.

Fredrickson, B. L.

2013 Love 2.0: How Our Supreme Emotion Affects Everything We Feel, Think, Do, and Become. New York, NY: Hudson Street Press.

Fredrickson, B. L.

1998 “What good are positive emotions?” Review of General Psychology, 2: 300-319.

Frost, P., L.F. Moore, M.R. Louis, C.C. Lundberg, and J. Martin. (Eds)

1991 Reframing Organizational Culture. Newbury Park, CA: Sage.

Gambassi, G., F. Landi, K. L. Lapane, A. Sgadari, V. Mor, and R. Bernabei 
1999 "Predictors of mortality in patients with Alzheimer's disease living in nursing homes." Journal of Neurological Neurosurgery Psychiatry, 67: 59-65.

Geertz, C.

1973 The Interpretation of Cultures. New York, NY: Basic Books.

Gibson, D. E., and R.R. Callister

2010 "Anger in organizations: Review and integration." Journal of Management, 36(1), 66-93.

Gil, K.M., J.M. Carson, L. S. Porter, C. Scipio, S.M. Bediako, and E. Orringer

2004 "Daily mood and stress predict pain, health care use, and work activity in African American adults with sickle-cell disease." Health Psychology, 23, 267-274.

Goffman, E.

1959 "The presentation of self in everyday life." In C. E. Izard (ed.), Anchoring of the Causes and Consequences of Emotional States. Garden City: Doubleday.

Goffman, E.

1983 “The Interaction Order: American Sociological Association, 1982 Presidential Address.” American Sociological Review, 48: 1-17.

Gonzaga, G. C., D. Keltner, E. A. Londahl, and M. D. Smith

2001 "Love and the commitment problem in romantic relations and friendship." Journal of Personality and Social Psychology, 81: 247-262.

Goodwin, P. E., and R. C. Intrieri

2006 "The influence of changing emotional goals on the psychological well-being of nursing home residents.” In L. Hyer and R.C. Intrieri (eds.), Geropsychological Interventions in Long-term Care: 185-206. New York: Springer Publishing.

Grandey, A. A.

2003 "When "the show must go on": Surface acting and deep acting as determinants of emotional exhaustion and peer-rated service delivery." Academy of Management Journal, 17: 419-436.

Grandey, A. A., G. M. Fisk, and D. D. Steiner

2005 "Must service with a smile be stressful? The moderating role of personal control for American and French employees.” Journal of Applied Psychology, 90: 893-904.

Gross, J. J., and O. P. John

2003 "Individual differences in two emotion regulation processes: Implications for affect, relationships, and well-being." Journal of Personality and Social Psychology, 85: 348-362.

Hackett, R. D., P. Bycio, and R. M. Guion

1989 "Absenteeism among hospital nurses: An idiographic-longitudinal analysis." Academy of Management Journal, 32, 424-453.

Hall, S., P. Hamiltion, H. Lidchi, S. Nixon, and C. Gledhill 
1997 “The work of representation.” In S. Hall (ed.), Representation: Cultural representations and signifying practices (Vol. 2): 13-74. London: SAGE Publications Limited.

Hamel, G., and B. Breen

2007 The Future of Management(p69-82). Boston, MA: Harvard Business School Publishing.

Hareli, S., and A. Rafaeli

2008 "Emotion cycles: On the social influence of emotion in organizations." Research in Organizational Behavior, 28: 35-59.

Harrison, D. A., D. A. Newman, and P. L. Roth

2006 "How important are job attitudes? Meta-analytic comparisons of integrative behavioral outcomes and time sequences." Academy of Management Journal, 49: 305-325.

Hatch, M. J.

1993 "The dynamics of organizational culture." The Academy of Management Review, 18, 657-693.

Hatfield, E., and R. Rapson

1993 Love, Sex, and Intimacy: Their Psychology, Biology, and History. New York, NY: HarperCollins.

Hatfield, E., and R. Rapson

2000 "Love and attachment processes." Handbook of Emotions: 595-654. New York, NY: Guilford Press.

Hatfield, E., J. T. Cacioppo, and R. L. Rapson

1993 "Emotional contagion." Current Directions in Psychological Science, 2: 96-99.

Hatfield, E., Hsee, C.K., Costello, J, Weisman, M.S., and C. Denney

1995 "The impact of vocal feedback on emotional experience and expression." Journal of Social Behavior and Personality, 10: 293-312.

Hausknecht, J. P., N. J. Hiller, and R. J. Vance

2008 "Work-unit absenteeism: Effects of satisfaction, commitment, and labor market conditions, and time." Academy of Management Journal, 51 1223-1245.

Hayward, R. M., and M. R. Tuckey

2011 "Emotions in uniform: How nurses regulate emotion at work via emotional boundaries." Human Relations, 64: 1501-1523.

Heaphy, E. D., and J. E. Dutton

2008 "Positive social interactions and the human body at work: Linking organizations and physiology." Academy of Management Review, 33: 137-162.

Hersey, R.B.

1932 "Workers Emotions in shop and home: A study of individual workers from the psychological and physiological standpoint.” Philadelphia, PA: University of Pennsylvania Press.

Hertenstein, M. J., D. Keltner, B. App, A. Bulleit, and R. Jaskolka 
Hobfoll, S.E., and A. Shirom

2001 "Conservation of resources theory: Applications to stress and management in the workplace." In R.T. Golembiewski (ed.), Handbook of Organizational Behavior ( $2^{\text {nd }}$ ed): 57-80. New York: Marcel Dekker.

Hochschild, A. R.

1983 The Managed Heart: The Commercialization of Human Feeling Berkeley. Berkeley, CA: The University of California Press.

Hofmann, D. A., and M. B. Gavin

1998 "Centering decisions in hierarchical linear models: Implications for research in organizations." Journal of Management, 24: 623-641.

Hotaling, D. L.

1990 "Adapting the mealtime environment: setting the stage for eating." Dysphagia, 5, 77-83.

Huang, J., R. Neufeld, A. Likourezos, B. Breuer, A. Khaski, E. Milano, and L. Libow

2003 "Sociodemographic and health characteristics of older Chinese on admission to a nursing home: A cross-racial/ethnic study." Journal of the American Geriatrics Society, 51: 404-409.

Isen, A. M.

1984 “Toward Understanding the Role of Affect in Cognition." Handbook of Social Cognition, 179-236.

Izard, C. E., Kagan, J., and R.B. Zajonc

1988 Emotions, cognition, and behavior. Cambridge: Cambridge University Press.

Jablonski, R. A., S. W. Utz, R. Steeves, and D. P. Gray

2007 “Decision about transfer from nursing home to emergency department." Journal of Nursing Scholarship, Third Quarter: 266-272.

Jackson, J.

1966 "A conceptual and measurement model for norms and roles." The Pacific Sociological Review, 9(1), $35-47$.

Jackson, $\mathrm{T}$.

1998 Inside Intel: Andy Grove and the Rise of the World's Most Powerful Chip Company. New York, NY: Plume.

Jacques, R.

1993 "Untheorized dimensions of caring work: Caring as a structural practice and caring as a way of seeing." Nursing Administrative Quarterly, 17, 1-10.

Johnson, S. K.

2008 I second that emotion: Effects of emotional contagion and affect at work on leader and follower outcomes. The Leadership Quarterly, 19, 1-19. 
Kahn, W. A.

1993 "Caring for the caregivers: Patterns of organizational caregiving." Administrative Science Quarterly, 38: 539-563.

Kahn, W. A.

1998 "Relational systems at work.” In B. M. Staw and L. L. Cummings (ed.), Research in Organizational Behavior: 39-76. US: Elsevier Science/JAI Press.

Kane, R. A., K. C. Kling, B. Berhadsky, R. L. Kane, K. Giles, H. B. Degenholtz, J. Liu, and L. J. Cutler 2003 "Quality of life measures for nursing home residents." Journal of Gerontology, 58a: 240-248.

Kanov, J. M., Maitlis, S., Worline, M. C., Dutton, J. E., Frost, P. J., and J.M. Lilius

2004 "Compassion in organizational life." American Behavioral Scientist, 47: 808-827.

Kellehear, A., E. Pugh, and L. Atter

2009 "Home away from home? A case study of bedside objects in a hospice." International Journal of Palliative Nursing, 15(3), 148-152.

Kellett, U. M.

1999 "Searching for new possibilities to care: A qualitative analysis of family caring involvement in nursing homes." Nursing Inquiry, 6: 9-16.

Kelman, $\mathrm{H}$.

1958 "Communing and relating." The American Journal of Psychoanalysis 18(1): 77-98.

Keltner, D., and J. J. Gross

1999 "Functional accounts of emotions." Cognition and Emotion, 13: 467-480.

Keltner, D., and J. Haidt

1999 "Social functions of emotions at four levels of analysis." Cognition and Emotion, 13: 505-521.

Kitayama, S., H.R. Markus, and M. Kurokawa

2000 "Culture, emotion, and well-being: Good feelings in Japan and the United States." Cognition and Emotion, 14: 93-124.

Kleinginna, Jr., P.R, and A. Kleinginna

1981 "A categorized list of emotion definitions, with suggestions for a consensual definition." Motivation and Emotion, 5: 345-379.

Kosfeld, M., M. Heinrichs, P. J. Zak, U. Fischbacher, and E. Fehr

2005 "Oxytocin increases trust in humans." Nature, 435: 673-676.

Kraft, T.L., and S.D. Pressman

2012 "Grin and bear it: The influence of manipulated facial expression on the stress response." Psychological Science, 23, 1372-1378. 
Krull, J. L., and D.P. MacKinnon

1999 "Multilevel mediation modeling in group-based intervention studies." Evaluation Review, 23(4), 418-444.

Langer, E., and J. Rodin

1976 "The effect of choice and enhanced personal responsibility for the aged: A field experiment in an institutional setting." Journal of Personality and Social Psychology 34(2): 191-198.

Lasswell, T.E., and M.E. Lasswell

1976 "I love you but I'm not in love with you." Journal of Marriage and Family Counseling, 2: 211-224.

Lawler, E. J.

2001 “An affect theory of social exchange." American Journal of Sociology, 107: 321-352.

Lawton, M.P., K. Van Haitsma, and J. Klapper

1996 “Observed affect in nursing home residents with Alzheimer's Disease.” Journal of Gerontology; Psychological Sciences, 51B: 3-14.

Lazarus, R. S.

1991 "Progress on a cognitive-motivational-relational theory of emotion." American Psychologist, 46: 819-834.

Levy, R. I.

1973 Tahitians: Mind and Experience in the Society Islands. Chicago, IL: University of Chicago Press.

Lewis, P.

2005 "Suppression or expression: An exploration of emotion management in a special care baby unit." Work, Employment and Society, 19: 565-581.

Li, S.

2003 “'Symbiotic niceness': Constructing a therapeutic relationship in psychosocial palliative care." Social Science and Medicine, 58: 2571-2583.

Lilius, J. M., M. C. Worline, J. Kanov, J. E. Dutton, P. Frost, and S. Maitlis

2005 "Exploring the Contours of Compassion at Work." Working Paper, University of Michigan Center for Positive Organizational Scholarship.

Lilius, J. M., M. C. Worline, S. Maitlis, J. Kanov, J. E. Dutton, and P. Frost

2008 "The contours and consequences of compassion at work." Journal of Organizational Behavior, 29: 193-218.

Lilius, J. M., M. C. Worline, J. E. Dutton, J. M. Kanov, and S. Maitlis

2011 "Understanding compassion capability." Human Relations, 64: 873-899.

Littell, R. C., G. A. Milliken, W. W. Stroup, and R. D. Wolfinger

2002 SAS system for mixed models. Cary, NC: SAS Institute Inc. 
Lorsch, J.W., G.W. Loveman, and J. Horn

1990 “American Airlines." HBS No. 491-044. Boston: Harvard Business School Publishing.

Lutz, C.

1988 Unnatural Emotions: Everyday Sentiments on a Micronesian Atoll and their Challenge to Western Theory. Chicago, IL: University of Chicago Press.

Lyubomirsky, S. L. King, and E. Diener

2005 "The benefits of frequent positive affect. Does happiness lead to success? Psychological Bulletin, 131: 803-855.

Magai, C., C. Cohen, D. Gomberg, C. Malatesta, and C. Culver

1996 "Emotional expression during mid-to-late-stage dementia." International Psychogeriatrics, 8: 383 395.

Malatesta, C. Z., and J.M. Haviland

1982 "Learning display rules: The socialization of emotion expression in infancy." Child Development, 53: 991-1003.

Malinowski, B.

1944 A Scientific Theory of Culture, and Other Essays. Chapel Hill, NC: University of North Carolina Press.

Markus, S., and S. Kitayama

1991 "Culture and the self: Implications for cognition, emotion, and motivation." Psychological Review, 98: 224-253.

Maslach, C., and S. E. Jackson

1981 “The measurement of experienced burnout." Journal of Occupational Behaviour, 2: 99-113.

Mayer J.D, P. Salovey, and D. R. Caruso

2000 "Models of emotional intelligence." In R.J. Sternberg (ed), Handbook of Intelligence: 396-420. Cambridge: Cambridge University Press.

McClelland, D. C.

1958 "Methods of measuring human motivation." Motives in fantasy, action, and society. Princeton, NJ: Van Nostrand.

McGilton, K. S.

2002 "Enhancing relationships between care providers and residents in long-term care: Designing a model of care.” Journal of Gerontological Nursing, 28: 13-21.

McGilton, K. S., and V.M. Boscart

2007 "Close care provider-resident relationships in long-term care environments." Journal of Clinical Nursing, 16: 2149-2157.

McRae, K., K. N. Ochsner, I. B. Mauss, J. J. D. Gabrieli, and J. J. Gross 
2008 “Gender Differences in Emotion Regulation: An fMRI Study of Cognitive Reappraisal.” Group Processes \& Intergroup Relations, 11: 143-162.

Medical Center of Aurora.

2013 http://auroramed.dotcms.org/careers/employee_voices.htm.

Mehrabian, A.

1972 Nonverbal Communication. Chicago, IL: Aldine-Atherton.

Merton, R. K.

1968 Social Theory and Social Structure. New York, NY: The Free Press.

Meyerson, D.E.

1994 Interpretations of stress in institutions: The cultural production of ambiguity and burnout. Administrative Science Quarterly, 39: 628-653.

Miller, K.I.

2007 "Compassionate communication in the workplace: Exploring processes of noticing, connecting, and responding.” Journal of Applied Communication Research, 35: 223-245.

Morris, J. N., B. E. Fries, D. R. Mehr, C. Hawes, C. Phillips, V. Mor, and L.A. Lipsitz

1994 “MDS Cognitive Performance Scale.” Journal of Gerontology, 49: M174-M182.

Nesse, R.M.

1990 "Evolutionary explanations of emotions." Human Nature, 1, 261-289.

Ong, A. D.

2010 "Pathways linking positive emotion and health in later life." Current Directions in Psychological Science 19(6): 358-362.

O'Reilly, C. A., and J. A. Chatman

1996. "Culture as social control: Corporations, cults, and commitment." Research in Organizational Behavior, 18: 157-200.

O'Reilly, C. A., J.A. Chatman, and D.F. Caldwell

1991 "People and organizational culture: A profile comparison approach to assessing person-organization fit." Academy of Management Journal, 34: 487-516.

Ozcelik, H.

2013 “An empirical analysis of surface acting in intra-organizational relationships.” Journal of Organizational Behavior, 34: 291-309.

Parkinson, B.

2005 "Facial movements express emotions or communicate motives?” Personality and Social Psychology Review, 9: 278-311. 
Parkinson, B., A. H. Fischer, and A. S. Manstead

2005 Emotion in Social Relations. New York: Psychology Press.

Pennington, K., J. Scott, and K. Magilvy

2003 "The role of certified nursing assistants in nursing homes." Journal of Nursing Administration, 33 : 578-584.

PepsiCo website

2012 "PepsiCo Values and Philosophy." http://www.pepsico.com/Company/PepsiCo-Values-andPhilosophy.html.

Rafaeli, A., and R. I. Sutton

1987 "Expression of Emotion as Part of the Work Role." Academy of Management Review, 12: 23-37.

Rafaeli, A., and I. Vilnai-Yavetz

2004 "Emotion as a connection of physical artifacts and organizations." Organization Science, 15: 671686.

Reis, H.R., and A. Aron

2008 "Love: What is it, why does it matter, and how does it operate?" Perspectives on Psychological Science, 3: 80-86.

Repetti, R.K.

1987 "Individual and common components of the social environment at work and psychological wellbeing." Journal of Personality and Social Psychology, 52: 710-720.

Rigby, J., S. Payne, and K. Froggatt

2010 "What evidence is there about the specific environmental needs of older people who are near the end of life and are cared for in hospices or similar institutions? A literature review." Palliative Medicine, 24(3), 268-285.

Robinson, M. D., E. R. Watkins, and E. Harmon-Jones

2013 Handbook of cognition and emotion. New York: Guilford Press.

Rosaldo, M. Z.

1984 "Toward an anthropology of self and feeling." In R. A. Shweder and R. A. LeVine, (eds.), Culture Theory: Essays on Mind, Self, and Emotion. Cambridge, UK: Cambridge University Press.

Roethlisberger, F. J., and W. J. Dickson

1939 Management and the Worker. Cambridge, MA: Harvard University Press.

Rousseau, D.M.

1990 “Assessing organizational culture: The case for multiple methods." In B. Schneider, (ed.), Organizational Climate and Culture: 153-192. San Francisco, CA: Jossey-Bass Publishers.

Ruckdeschel, K., and K. Van Haitsma 
2004 “A workshop for nursing home staff: Recognizing and responding to their own and residents' emotions." Gerontology and Geriatrics Education, 24: 39-51.

Rynes, S. L., J. M. Bartunek, J. E. Dutton, and J. D. Margolis

2012 "Care and compassion through an organizational lens: Opening up new possibilities." Academy of Management Review, 37: 503-523.

Sackmann, S.A.

1992 Culture and subcultures: An analysis of organizational knowledge. Administrative Science Quarterly, $37,140-161$.

Schein, E. H.

1990 “Organizational Culture.” American Psychologist, 45: 109-119.

Schein, E.H.

1991. “What is culture?” In P.J. Frost (Ed.), Reframing organizational culture (pp. 243-253). Newbury Park, Calif.: Sage Publications.

Schein, E. H.

2010 Organizational Culture and Leadership (4 ${ }^{\text {th }}$ ed.). San Francisco, CA: Jossey-Bass.

Scott, R. A., L. H. Aiken, D. Mechanic, and J. Moravcsik

1995 "Organizational aspects of caring." The Milbank Quarterly, 73: 77-95.

Seeman, T. E., and S. L. Syme

1987 "Social networks and coronary artery disease: a comparison of the structure and function of social relations as predictors of disease." Psychosomatic Medicine, 49: 341-354.

Seeman, T. E., B. H. Singer, C. D. Ryff, G. D. Love, and L. Levy-Storms

2002 "Social relationships, gender, and allostatic load across two age cohorts." Psychosomatic medicine, 64: 395-406.

Shaver, P. R., J. Schwartz, D. Kirson, and C. O'Connor

1987 "Emotion knowledge: Further exploration of a prototype approach." Journal of Personal Social Psychology, 52: 1061-1086.

Sheldon, O.

1923 The Philosophy of Management. London: Sir I. Pitman and Sons.

Sherif, M.

1936 The Psychology of Social Norms. Oxford, England: Harper.

Shuler, S., and B.D. Sypher

2000 "Seeking Emotional Labor: When Managing the Heart Enhances the Work Experience." Management Communication Quarterly, 14: 50-89. 
Siehl, C., and J. Martin

1990 Organizational culture: A key to financial performance? In B. Schneider (Ed.), Organizational Climate and Culture (pp. 241-281). San Francisco: Jossey Bass.

Smircich, L.

1983 Concepts of culture and organizational analysis. Administrative Science Quarterly, 28: 339-358.

Snijders, T. A., and R. J. Bosker

2011 Multilevel analysis: An introduction to basic and advanced multilevel modeling. Thousand Oaks: Sage Publications Limited.

Solomon, R. C.

1998 "The moral psychology of business: Care and compassion in the corporation." Business Ethics Quarterly, 8, 515-533.

Spreitzer, G. M.

1996 "Social structural characteristics of psychological empowerment." Academy of Management Journal, 39: 483-504.

Staw, B. M., N. E. Bell, and J. A. Clausen

1986 "The dispositional approach to job attitudes: A lifetime longitudinal test." Administrative Science Quarterly, 31: 56-77.

Sternberg, R. J.

1988 “Triangulating Love” In R.J. Sternberg and M.L. Barnes (eds). The Psychology of Love: 119-138. New Haven: Yale University Press.

Stone, R. I.

2000 "Long-term care for the disabled elderly: Current policy, emerging trends and implications for the $21^{\text {st }}$ century." Milbank Quarterly, 78: electronic report.

Strack, F., L. L. Martin, and S. Stepper

1988 "Inhibiting and facilitating conditions of the human smile: A nonobtrusive test of the facial feedback hypothesis.” Journal of Personality and Social Psychology, 54: 768-777.

Strati, A.

2005 "Organizational artifacts and the aesthetic approach." In A. Rafaeli and M. Pratt (Eds) Artifacts and Organizations: Beyond Mere Symbolism. New York: Erlbaum.

Taylor, F. W.

1911 The Principles of Scientific Management. New York, NY, USA and London, UK: Harper \& Brothers.

Teresi, J. A., R. Abrams, D. Holmes, M. Ramirez, and J. P. Emicke

2001 "Prevalence of depression and depression recognition in nursing homes." Social Psychiatry and Psychiatric Epidemiology, 36: 613-620. 
Tetz, K. B., P. G. Archbold, B. J. Stewart, D. Messecar, M. C. Hornbrook, and S. A. Lucas

2006 "How frail elders evaluate their caregiver's enactment: A scale to measure affection, skill, and attentiveness." Journal of Family Nursing, 12: 251-275.

Tracy, J. L., and R. W. Robins

2008 "The automaticity of emotion recognition." Emotion, 8: 81-95.

Trice, H. M., and J. M. Beyer

1993 The Cultures of Work Organizations. Englewood Cliffs, NJ: Prentice Hall.

Tugade, M. M., and B. L. Fredrickson

2004 "Resilient individuals use positive emotions to bounce back from negative emotional experiences." Journal of Personality and Social Psychology, 86: 320-333.

Turnbull, C.

1972 The Mountain People. New York: Simon and Schuster

Turner, V. W.

1967 The Forest of Symbols: Aspects of Ndembu Ritual. Ithaca, NY: Cornell University Press.

U.S. Bureau of Labor Statistics

2011 American Time Use Survey.

van IJzendoorn, M.H., and M.J. Bakermans-Kranenburg

2012 "A sniff of trust: Meta-analysis of the effects of intranasal oxytocin administration on face recognition, trust to in-group, and trust to out-group." Psychoneuroendocrinology, 37: 438-443.

Van Maanen, J., and G. Kunda

1989 Real Feelings: Emotional expression and organizational culture. In B. Staw and L.L. Cummings (eds.) Research in Organizational Behavior, 11: 43-10. Greenwich, CT: JAI Press.

Von Dietze, E., and A. Org

2000 “Compassionate care: A moral dimension of nursing." Nursing Inquiry, 7: 166-174.

Wageman, R.

1995 “Interdependence and group effectiveness.” Administrative Science Quarterly, 40: 145-181.

Walster, E., and G.W. Walster

1978 A New Look at Love. Reading, MA: Addison-Wesley.

Watson, D., L.A. Clark, and A. Tellegen

1988 "Development and validation of brief measures of positive and negative affect: The PANAS scales." Journal of Personality and Social Psychology, 54(6): 1063-1070.

Watson, D., L.A. Clark, C.W. McIntyre, and S. Hamaker

1992 "Affect, personality, and social activity." Journal of Personality and Social Psychology, 43: 10111025. 
Watson, J. B.

1930 Behaviorism (Revised edition). Chicago: University of Chicago Press.

Weng, H.Y., Fox, A.S., Shackman, A.J., Stodola, D.E., Caldwell, J,Z,K., Olson, M.C., Rogers, G.M. and R.J. Davidson

2013 “Affect, personality, and social activity.” Psychological Science, 43: 1011-1025.

Weiner, A., and J. Ronch

2003 Culture Change in Long-term Care. New York, NY: Haworth Social Work Practice Press.

White, L. A.

1949 The Science of Culture: A Study of Man and Civilization. Oxford, England: Farrar, Straus.

Zappos

2013 http://about.zappos.com/our-unique-culture/zappos-core-values/build-positive-team-and-familyspirit. 
Table 1

Descriptive Statistics of Demographic Variables for Employees, Patients and Patients' Families

\begin{tabular}{|c|c|c|c|c|c|}
\hline & Percentage & Mean & S.D. & Min. & Max. \\
\hline \multicolumn{6}{|l|}{ Employee characteristics $(\mathrm{N}=185)$} \\
\hline \multicolumn{6}{|l|}{ Functional background } \\
\hline C.N.A. & $55.1 \%$ & & & & \\
\hline Nurse & $16.8 \%$ & & & & \\
\hline Unit Manager & $4.0 \%$ & & & & \\
\hline Therapeutic Recreation & $4.0 \%$ & & & & \\
\hline Housekeeping & $4.0 \%$ & & & & \\
\hline Dietician & $3.6 \%$ & & & & \\
\hline Social Workers & $3.3 \%$ & & & & \\
\hline Physicians & $2.6 \%$ & & & & \\
\hline Nursing Coordinator & $2.2 \%$ & & & & \\
\hline RAUM Nurses & $1.8 \%$ & & & & \\
\hline Food Service Worker & $1.1 \%$ & & & & \\
\hline Community Coordinator & $1.1 \%$ & & & & \\
\hline Other & $0.4 \%$ & & & & \\
\hline \multicolumn{6}{|l|}{ Shift } \\
\hline Day & $57.9 \%$ & & & & \\
\hline Evening & $21.6 \%$ & & & & \\
\hline Night & $20.5 \%$ & & & & \\
\hline \multicolumn{6}{|l|}{ Educational Attainment } \\
\hline Elementary school & $0.4 \%$ & & & & \\
\hline Junior high school & $2.0 \%$ & & & & \\
\hline High school & $28.2 \%$ & & & & \\
\hline Some college & $34.7 \%$ & & & & \\
\hline Undergraduate degree & $15.5 \%$ & & & & \\
\hline Some post-graduate education & $4.9 \%$ & & & & \\
\hline Masters degree & $7.8 \%$ & & & & \\
\hline $\mathrm{MD} / \mathrm{PhD}$ & $2.4 \%$ & & & & \\
\hline Other & $4.1 \%$ & & & & \\
\hline$\%$ Female & $81.3 \%$ & & & & \\
\hline Tenure with organization (months) & & 124.8 & 109.3. & 1 & 620 \\
\hline Tenure on unit (months) & & 64.7 & 67.5 & 1 & 361 \\
\hline \multicolumn{6}{|l|}{ Patient Characteristics $(\mathrm{N}=108)$} \\
\hline$\%$ Female & $64.2 \%$ & & & & \\
\hline Age (years) & & 83.7 & 9.8 & 43.8 & 104.85 \\
\hline Tenure at the long-term care facility (months) & & 38.4 & 35.5 & 0.8 & 166.7 \\
\hline Tenure on unit (months) & & 31.7 & 31.1 & 0.8 & 166.7 \\
\hline Poor Health (higher scores indicate poorer health) & & 4.3 & 1.9 & 1.0 & 9.0 \\
\hline $\begin{array}{l}\text { Poor Cognitive Functioning ( } 0-6 \text { scale } 0=\text { Intact through } \\
6=\text { Very Severe Impairment) }\end{array}$ & & 2.9 & 2.0 & 0.0 & 6.0 \\
\hline $\begin{array}{l}\text { Poor Physical Functioning (higher scores indicate poorer } \\
\text { physical functioning) }\end{array}$ & & 8.8 & 5.4 & 0.0 & 16.0 \\
\hline \multicolumn{6}{|l|}{ Family Member Characteristics (N=42) } \\
\hline Child & $68.2 \%$ & & & & \\
\hline Spouse & $11.4 \%$ & & & & \\
\hline Other Relative & $11.4 \%$ & & & & \\
\hline Friend & $4.5 \%$ & & & & \\
\hline Sibling & $2.3 \%$ & & & & \\
\hline Grandchild & $2.2 \%$ & & & & \\
\hline
\end{tabular}




\begin{tabular}{|c|c|c|c|c|c|c|c|c|c|c|c|}
\hline \multicolumn{12}{|c|}{ Table $2 a$} \\
\hline \multicolumn{12}{|c|}{ Bivariate Relationships Among All Employee Variables* } \\
\hline & & 1 & 2 & 3 & 4 & 5 & 6 & 7 & 8 & 9 & 10 \\
\hline 1 & Male & - & & & & & & & & & \\
\hline 2 & Tenure (T1) & $\begin{array}{r}.17 \bullet \\
(159)\end{array}$ & - & & & & & & & & \\
\hline 3 & Certified Nursing Assistant & $\begin{array}{c}.02 \\
(159)\end{array}$ & $\begin{array}{l}-.01 \\
(159)\end{array}$ & - & & & & & & & \\
\hline 4 & Trait PA (T1) & $\begin{aligned} .17 \bullet \\
(159)\end{aligned}$ & $\begin{array}{c}.04 \\
(159)\end{array}$ & $\begin{array}{l}-.13 \\
(159)\end{array}$ & - & & & & & & \\
\hline 5 & Social desirability (T1) & $\begin{array}{c}.03 \\
(159)\end{array}$ & $\begin{array}{c}.06 \\
(159)\end{array}$ & $\begin{array}{r}.20 \bullet \\
(159)\end{array}$ & $\begin{array}{l}.21 \bullet \bullet \\
(159)\end{array}$ & - & & & & & \\
\hline 6 & $\begin{array}{l}\text { Culture of companionate love - } \\
\text { Employee observations (T1) }\end{array}$ & $\begin{array}{c}.11 \\
(159)\end{array}$ & $\begin{array}{c}.12 \\
(159)\end{array}$ & $\begin{array}{c}-.00 \\
(159)\end{array}$ & $\begin{array}{l}.20 \bullet \\
(159)\end{array}$ & $\begin{array}{l}.07 \bullet \\
(159)\end{array}$ & - & & & & \\
\hline 7 & Employee teamwork (T2) & $\begin{aligned} .18 \bullet \\
(159)\end{aligned}$ & $\begin{array}{c}.10 \\
(159)\end{array}$ & $\begin{array}{r}.10 \\
(159)\end{array}$ & $\begin{array}{l}.14 \\
(159)\end{array}$ & $\begin{array}{l}.30 \bullet \bullet \\
(159)\end{array}$ & $\begin{array}{l}.27 \bullet \bullet \\
(159)\end{array}$ & - & & & \\
\hline 8 & Employee satisfaction (T2) & $\begin{array}{r}.19 \bullet \\
(158)\end{array}$ & $\begin{array}{c}.04 \\
(158)\end{array}$ & $\begin{array}{c}-.01 \\
(158)\end{array}$ & $\begin{array}{l}.18 \\
(158)\end{array}$ & $\begin{array}{l}.30 \bullet \bullet \bullet \\
(158)\end{array}$ & $\begin{array}{l}.25 \bullet \bullet \\
(158)\end{array}$ & $\begin{array}{l}.60 \bullet \bullet \\
(158)\end{array}$ & - & & \\
\hline 9 & Emotional exhaustion (T2) & $\begin{array}{c}-.13 \\
(159)\end{array}$ & $\begin{array}{r}.16 \bullet \\
(159)\end{array}$ & $\begin{array}{r}-.02 \\
(159)\end{array}$ & $\begin{array}{l}-.27 \bullet \bullet \bullet \\
(159)\end{array}$ & $\begin{array}{l}-.29 \bullet \bullet \bullet \\
(159)\end{array}$ & $\begin{array}{l}-.07 \\
(159)\end{array}$ & $\begin{array}{c}-.39 \bullet \bullet \bullet \\
(159)\end{array}$ & $\begin{array}{c}-.53 \bullet \bullet \bullet \\
(158)\end{array}$ & - & \\
\hline 10 & Absenteeism (T2) & $\begin{array}{c}.05 \\
(142)\end{array}$ & $\begin{array}{c}.09 \\
(142)\end{array}$ & $\begin{array}{l}.29 \bullet \bullet \\
(142)\end{array}$ & $\begin{array}{l}-.10 \\
(142)\end{array}$ & $\begin{array}{l}.00 \\
(142)\end{array}$ & $\begin{array}{l}-.08 \\
(142)\end{array}$ & $\begin{array}{l}-.08 \\
(142)\end{array}$ & $\begin{array}{l}-.17 \bullet \\
(141)\end{array}$ & $\begin{array}{c}.03 \\
(142)\end{array}$ & - \\
\hline
\end{tabular}

$\bullet \mathrm{p}<.05, \cdots \mathrm{p}<.01, \cdots \mathrm{p}<.001$; two-tailed tests.

$*$ Number of participants in parentheses. These correlations are based on single-level analysis, pooled estimates of variance. $\mathrm{T} 1=$ Time $1 ; \mathrm{T} 2=$ Time 2 (16 months later $)$ 


\begin{tabular}{|c|c|c|c|c|c|c|c|c|c|c|c|}
\hline \multicolumn{12}{|c|}{ Table $2 b$} \\
\hline \multicolumn{12}{|c|}{ Bivariate Relationships Among All Patient Variables* } \\
\hline & & 1 & 2 & 3 & 4 & 5 & 6 & 7 & 8 & 9 & 10 \\
\hline 1 & Poor health (T2) & - & & & & & & & & & \\
\hline 2 & Cognitive impairment (T2) & $\begin{array}{l}.17 \\
(101)\end{array}$ & - & & & & & & & & \\
\hline 3 & Poor physical functioning (T2) & $\begin{array}{l}.31 \bullet \bullet \\
(101)\end{array}$ & $\begin{array}{l}.44 \bullet \bullet \bullet \\
(101)\end{array}$ & - & & & & & & & \\
\hline 4 & $\begin{array}{l}\text { Pleasant mood - } \\
C N A \text { Ratings (T2) }\end{array}$ & $\begin{array}{l}.06 \\
(101)\end{array}$ & $\begin{aligned}-.31 \bullet \bullet \\
(101)\end{aligned}$ & $\begin{array}{l}-.25 \bullet \\
(101)\end{array}$ & - & & & & & & \\
\hline 5 & Satisfaction (T2) & $\begin{array}{l}-.17 \\
(32)\end{array}$ & $\begin{array}{l}.15 \\
(32)\end{array}$ & $\begin{array}{l}-.34 \\
(32)\end{array}$ & $\begin{array}{l}.02 \\
(31)\end{array}$ & - & & & & & \\
\hline 6 & $\begin{array}{l}\text { Quality of life - } \\
\text { Dignity (T2) }\end{array}$ & $\begin{array}{l}.25 \\
(29)\end{array}$ & $\begin{array}{l}.12 \\
(29)\end{array}$ & $\begin{array}{l}-.16 \\
(29)\end{array}$ & $\begin{array}{l}.17 \\
(28)\end{array}$ & $\begin{array}{l}.76 \bullet \bullet \bullet \\
(29)\end{array}$ & - & & & & \\
\hline 7 & $\begin{array}{l}\text { Quality of life - } \\
\text { Good relationships (T2) }\end{array}$ & $\begin{array}{r}-.01 \\
(29)\end{array}$ & $\begin{array}{l}-.02 \\
(29)\end{array}$ & $\begin{array}{c}-.06 \\
(29)\end{array}$ & $\begin{array}{l}-.05 \\
(28)\end{array}$ & $\begin{array}{l}.64 \bullet \bullet \bullet \\
(29)\end{array}$ & $\begin{array}{l}.60 \bullet \bullet \bullet \\
(29)\end{array}$ & - & & & \\
\hline 8 & Weight gain (T2) & $\begin{array}{r}-.11 \\
(99)\end{array}$ & $\begin{array}{l}.06 \\
(99)\end{array}$ & $\begin{array}{c}-.08 \\
(99)\end{array}$ & $\begin{array}{l}-.19 \\
(93)\end{array}$ & $\begin{array}{l}.36 \\
(27)\end{array}$ & $\begin{array}{l}.50 \bullet \\
(24)\end{array}$ & $\begin{array}{l}.54 \bullet \bullet \\
(24)\end{array}$ & - & & \\
\hline 9 & Fewer trips to emergency room (T2) & $\begin{array}{l}.14 \\
(101)\end{array}$ & $\begin{array}{l}.07 \\
(101)\end{array}$ & $\begin{array}{l}.14 \\
(101)\end{array}$ & $\begin{array}{l}-.13 \\
(100)\end{array}$ & $\begin{array}{l}.09 \\
(32)\end{array}$ & $\begin{array}{l}-.05 \\
(29)\end{array}$ & $\begin{array}{r}-.06 \\
(29)\end{array}$ & $\begin{array}{l}.03 \\
(98)\end{array}$ & - & \\
\hline 10 & Lower incidence of ulcers (T2) & $\begin{array}{l}-.04 \\
(101) \\
\end{array}$ & $\begin{array}{l}.14 \\
(101) \\
\end{array}$ & $\begin{array}{l}.21 \bullet \\
(101)\end{array}$ & $\begin{array}{r}.00 \\
(99) \\
\end{array}$ & $\begin{array}{l}.22 \\
(32) \\
\end{array}$ & $\begin{array}{l}.12 \\
(29) \\
\end{array}$ & $\begin{array}{l}.25 \bullet \\
(29) \\
\end{array}$ & $\begin{array}{l}-.03 \\
(97) \\
\end{array}$ & $\begin{array}{c}.11 \\
(100) \\
\end{array}$ & - \\
\hline
\end{tabular}

$\bullet \mathrm{p}<.05, \bullet \mathrm{p}<.01, \cdots \mathrm{p}<.001 ;$ two-tailed tests.

$*$ Number of participants in parentheses. These correlations are based on single-level analysis, pooled estimates of variance. $\mathrm{T} 1=$ Time $1 ; \mathrm{T} 2=$ Time 2 (16 months later $)$ 


\begin{tabular}{|c|c|c|c|c|c|c|c|}
\hline \multicolumn{8}{|c|}{ Table 2c } \\
\hline \multicolumn{8}{|c|}{ Bivariate Relationships Among All Patients' Family Member Variables* } \\
\hline & & 1 & 2 & 3 & 4 & 5 & 6 \\
\hline 1 & Patient poor health (T2) & 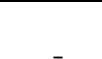 & & & & & \\
\hline 2 & Patient cognitive impairment (T2) & $\begin{array}{l}.17 \\
(101)\end{array}$ & - & & & & \\
\hline 3 & Patient poor physical functioning (T2) & $\begin{array}{l}.31 \bullet \bullet \\
(101)\end{array}$ & $\begin{array}{l}.44 \bullet \bullet \\
(101)\end{array}$ & - & & & \\
\hline 4 & $\begin{array}{l}\text { Culture of companionate love - } \\
\text { Family observations (T1) }\end{array}$ & $\begin{array}{c}-.13 \\
(41)\end{array}$ & $\begin{array}{r}-.08 \\
(41)\end{array}$ & $\begin{array}{l}-.23 \\
(41)\end{array}$ & - & & \\
\hline 5 & Family member satisfaction (T2) & $\begin{array}{l}.09 \\
(41)\end{array}$ & $\begin{array}{r}-.19 \\
(41)\end{array}$ & $\begin{array}{l}-.09 \\
(41)\end{array}$ & $\begin{array}{l}.39 \bullet \\
(41)\end{array}$ & - & \\
\hline 6 & $\begin{array}{l}\text { Family member would recommend } \\
\text { to others (T2) }\end{array}$ & $\begin{array}{r}-.18 \bullet \\
(40)\end{array}$ & $\begin{array}{c}-.06 \\
(40) \\
\end{array}$ & $\begin{array}{r}-.14 \\
(40) \\
\end{array}$ & $\begin{array}{l}.44 \bullet \bullet \\
(40)\end{array}$ & $\begin{array}{c}.50 \bullet \bullet \\
(40) \\
\end{array}$ & - \\
\hline
\end{tabular}

$\bullet \mathrm{p}<.05, \bullet \mathrm{p}<.01, \cdots \mathrm{p}<.001 ;$ two-tailed tests.

$*$ Number of participants in parentheses. These correlations are based on single-level analysis, pooled estimates of variance. $\mathrm{T} 1=$ Time $1 ; \mathrm{T} 2=$ Time 2 (16 months later) 
Table 3

Longitudinal Models Predicting Employee Engagement and Withdrawal from Work at Time 2 from Outside Raters' Observations of the Culture of Companionate Love at Time ${ }^{*}$

\begin{tabular}{|c|c|c|c|c|}
\hline Time 1 Predictor Variables & $\begin{array}{l}\text { Time } 2 \\
\text { Employee } \\
\text { Emotional } \\
\text { Exhaustion }^{\mathrm{a}} \\
\end{array}$ & $\begin{array}{l}\text { Time } 2 \\
\text { Employee } \\
\text { Absenteeism } \\
\end{array}$ & $\begin{array}{l}\text { Time } 2 \\
\text { Employee } \\
\text { Teamwork } \\
\end{array}$ & $\begin{array}{l}\text { Time } 2 \\
\text { Employee } \\
\text { Satisfaction } \\
\end{array}$ \\
\hline Site 1 & -.18 & $-.47 \bullet$ & .00 & .02 \\
\hline Site 2 & -.32 & -.22 & .29 & .23 \\
\hline Male & -.22 & .02 & $.31 \bullet$ & .24 \\
\hline Tenure & .00 & .00 & .00 & .00 \\
\hline Certified nursing assistant (CNA) & .05 & $.55 \bullet \bullet$ & .08 & -.11 \\
\hline Social desirability & $-1.78 \bullet \bullet$ & -.34 & $1.39 \bullet \bullet$ & $1.49 \bullet \bullet$ \\
\hline Trait positive affectivity & $-.28 \bullet$ & -.02 & .05 & .05 \\
\hline $\begin{array}{l}\text { Culture of companionate love - } \\
\text { Outsider raters' observations }\end{array}$ & $-.40 \bullet$ & $-.21 \bullet$ & $.56 \bullet$ & $.51 \bullet \bullet$ \\
\hline Pseudo R ${ }^{2}$ & .13 & .08 & .10 & .16 \\
\hline
\end{tabular}

*Unstandardized coefficients are reported. Time 2 measures were collected 16 months after Time $1 .{ }^{a} \mathrm{n}=156$ observations nested in 13 units; $^{\mathrm{b}} \mathrm{n}=137$ observations nested in 13 units. $^{\mathrm{c}} \mathrm{n}=120$ observations nested in 13 units. $\bullet p<.05, \bullet p<.01$, two-tailed tests (control variables), one-tailed test (culture of companionate love).

Table 4

Longitudinal Models Predicting Employee Engagement and Withdrawal from Work at Time 2 from Employees' Observations of the Culture of the Companionate Love at Time $1^{*}$

\begin{tabular}{|c|c|c|c|c|}
\hline Time 1 Predictor Variables & $\begin{array}{l}\text { Time } 2 \\
\text { Employee } \\
\text { Emotional } \\
\text { Exhaustiona }^{a}\end{array}$ & $\begin{array}{l}\text { Time } 2 \\
\text { Employee } \\
\text { Absenteeism }\end{array}$ & $\begin{array}{l}\text { Time } 2 \\
\text { Employee } \\
\text { Teamwork }\end{array}$ & $\begin{array}{l}\text { Time } 2 \\
\text { Employee } \\
\text { Satisfaction }\end{array}$ \\
\hline Site 1 & -.15 & $-.66 \bullet$ & .07 & .05 \\
\hline Site 2 & -.13 & -.12 & .01 & -.02 \\
\hline Male & -.29 & .02 & $.29 \bullet$ & $.28 \bullet$ \\
\hline Tenure & .00 & .00 & .00 & .00 \\
\hline Certified nursing assistant (CNA) & .02 & $.56 \bullet \bullet$ & .08 & -.09 \\
\hline Social desirability & $-1.70 \bullet \bullet$ & -.47 & $1.37 \bullet \bullet$ & $1.40 \bullet \bullet$ \\
\hline Trait positive affectivity (PA) & $-.37 \bullet \bullet$ & .02 & .05 & .08 \\
\hline $\begin{array}{l}\text { Culture of companionate love - } \\
\text { Employees' observations }\end{array}$ & -.07 & $-.14 \bullet$ & $.29 \bullet \bullet$ & $.27 \bullet \bullet$ \\
\hline $\begin{array}{l}\text { Culture of companionate love } * \text { Trait } \\
\text { positive affectivity }\end{array}$ & $-.30 \bullet$ & .08 & $.25 \bullet$ & $.41 \bullet \bullet$ \\
\hline Pseudo R ${ }^{2}$ & .13 & .10 & .20 & .26 \\
\hline
\end{tabular}

*Unstandardized coefficients are reported. Trait PA, social desirability, culture of companionate love, \& interaction terms are grand-mean centered. Time 2 measures collected 16 months later. ${ }^{a} \mathrm{n}=137$ observations nested in 13 units; $^{\mathrm{b}} \mathrm{n}=156$ observations nested in 13 units. $^{\mathrm{c}} \mathrm{n}=120$ observations nested in 13 units. $\bullet p<.05, \bullet p<.01, \cdots p<.001$, two-tailed tests (control variables), one-tailed test (culture of companionate love). 
Table 5

Longitudinal Models Predicting Patient Mood at Time 2 from Outside Raters' Observations of the Culture of Companionate Love at Time $1^{*}$

Predictor Variables

Time 2 Patient Pleasant Mood

Poor health (Time 2)

(as rated by primary Certified Nursing Assistants ${ }^{a}$

Cognitive impairment (Time 2)

$-.01$

Poor physical functioning (Time 2)

$-.14 \bullet \bullet$

Culture of companionate love -

$-.02$

$.46 \bullet$

Outside raters' observations (Time 1)

Pseudo R ${ }^{2}$

.15

*Unstandardized coefficients are reported. Time 2 measures collected 16 months later. a $\mathrm{n}=109$ observations nested in 13 units. $\bullet \mathrm{p}<.05, \cdots \mathrm{p}<.01, \cdots \mathrm{p}<.001$, two-tailed tests (control variables), one-tailed test (culture of companionate love).

Table 6

Longitudinal Models Predicting Patient Satisfaction and Quality of Life at Time 2 from Outside Raters' Observations of the Culture of Companionate Love at Time $1^{*}$

\begin{tabular}{|c|c|c|c|}
\hline Predictor Variables & $\begin{array}{l}\text { Time } 2 \\
\text { Patient } \\
\text { Satisfaction } \\
\end{array}$ & $\begin{array}{l}\text { Time } 2 \\
\text { Patient } \\
\text { Quality of Life - } \\
\text { Dignityb }\end{array}$ & $\begin{array}{l}\text { Time } 2 \\
\text { Patient } \\
\text { Quality of Life- } \\
\text { Good } \\
\text { Relationships }{ }^{\mathrm{b}}\end{array}$ \\
\hline Poor health (Time 2) & -.06 & .19 & $-.28 \bullet$ \\
\hline Cognitive impairment (Time 2) & $.33 \bullet$ & $.65 \bullet \bullet$ & .14 \\
\hline Poor physical functioning (Time 2) & $-.30 \bullet$ & $-.44 \bullet \bullet$ & -.05 \\
\hline $\begin{array}{l}\text { Culture of companionate love - } \\
\text { Outside raters' observations (Time 1) }\end{array}$ & $.60 \bullet \bullet$ & $.75 \bullet$ & $.57 \bullet$ \\
\hline Pseudo R² & .35 & .33 & .16 \\
\hline
\end{tabular}

* Unstandardized coefficients are reported. Time 2 measures collected 16 months later. ${ }^{a} \mathrm{n}=32$ observations nested in 13 units; $^{\mathrm{b}} \mathrm{n}=39$ observations nested in 13 units. $\bullet \mathrm{p}<.05, \bullet \mathrm{p}<.01$, $\cdots \mathrm{p}<.001$, two-tailed tests (control variables), one-tailed test (culture of companionate love). 
Table 7

Longitudinal Models Predicting Patient Health Outcomes at Time 2 from Outside Raters'

Observations of the Culture of Companionate Love at Time $1^{*}$

\begin{tabular}{|c|c|c|c|}
\hline Predictor Variables & $\begin{array}{l}\text { Time } 2 \\
\text { Patient } \\
\text { Weight Gain }\end{array}$ & $\begin{array}{l}\text { Time } 2 \\
\text { Fewer Patient Trips } \\
\text { to Emergency Room }\end{array}$ & $\begin{array}{l}\text { Time } 2 \\
\text { Lower } \\
\text { Incidence of } \\
\text { Patient Ulcers } \\
\end{array}$ \\
\hline Poor health (Time 2) & -.21 & .25 & -.31 \\
\hline Cognitive impairment (Time 2) & -.42 & .07 & -.19 \\
\hline Poor physical functioning (Time 2) & .16 & -.04 & $-1.16 \bullet \bullet \bullet$ \\
\hline $\begin{array}{l}\text { Culture of companionate love - } \\
\text { Outside raters' observations (Time 1) }\end{array}$ & .57 & $1.61 \bullet$ & .20 \\
\hline Pseudo R² & .00 & .65 & .22 \\
\hline
\end{tabular}

*Unstandardized coefficients are reported. Time 2 measures collected 16 months later. ${ }^{a} \mathrm{n}=114$

observations nested in 13 units; $^{\mathrm{b}} \mathrm{n}=111$ observations nested in 13 units. $\bullet \mathrm{p}<.05, \bullet \mathrm{p}<.01$, $\cdots \mathrm{p}<.001$, two-tailed tests (control variables), one-tailed test (culture of companionate love).

Table 8

Longitudinal Models Predicting Family Attitudes at Time 2 from Outsider Raters' Observations of the Culture of Companionate Love at Time 1*

\begin{tabular}{lll} 
& $\begin{array}{l}\text { Time 2 } \\
\text { Family Member } \\
\text { Satisfaction }\end{array}$ & $\begin{array}{l}\text { Time 2 } \\
\text { Family Member Would } \\
\text { Recommend to Others }^{a}\end{array}$ \\
\hline Predictor Variables & -.18 & -.32 \\
Site 1 & .38 & .19 \\
Patient Poor health (Time 2) & $.26 \bullet$ & $.31 \bullet$ \\
Patient Cognitive impairment (Time 2) & $-.43 \bullet \bullet$ & $-.47 \bullet \bullet$ \\
Patient Poor physical functioning (Time 2) & .17 & .11 \\
Culture of companionate love - & .32 & .29 \\
Outsider raters' observations (Time 1) & & .08 \\
Pseudo R & .07 & \\
\hline
\end{tabular}

*Unstandardized coefficients are reported. Time 2 measures collected 16 months later. Poor health, cognitive impairment, and poor physical functioning measures are for the family member in the hospital.

${ }^{a} \mathrm{n}=91$ observations nested in 13 units. $\cdot \mathrm{p}<.05, \bullet \mathrm{p}<.01, \cdots \mathrm{p}<.001$, two-tailed tests (control variables), one-tailed test (culture of companionate love). 
Table 9

Longitudinal Models Predicting Family Attitudinal Variables at Time 2 from Family Observations of the Culture of Companionate Love at Time $1 *$

\begin{tabular}{|c|c|c|}
\hline Predictor Variables & $\begin{array}{l}\text { Time } 2 \\
\text { Family Member } \\
\text { Satisfaction }\end{array}$ & $\begin{array}{l}\text { Time } 2 \\
\text { Family Member would } \\
\text { Recommend to Others }\end{array}$ \\
\hline Site 1 & .59 & .52 \\
\hline Site 2 & .52 & .46 \\
\hline Patient poor health (Time 2) & -.01 & .02 \\
\hline Patient cognitive impairment (Time 2) & $-.39 \bullet$ & $-.42 \bullet$ \\
\hline Patient poor physical functioning (Time 2) & .29 & .26 \\
\hline $\begin{array}{l}\text { Culture of companionate love - } \\
\text { Family observations (Time 1) }\end{array}$ & $.41 \bullet \bullet$ & $.49 \bullet \bullet$ \\
\hline Pseudo R ${ }^{2}$ & .22 & .26 \\
\hline
\end{tabular}

*Unstandardized beta coefficients. Time 2 measures collected 16 months later. Poor health, cognitive impairment, and poor physical functioning measures are for the family member in the hospital.

${ }^{\mathrm{a}} \mathrm{n}=47$ observations nested in 13 units. $\cdot \mathrm{p}<.05, \cdot \mathrm{p}<.01, \cdots \mathrm{p}<.001$, two-tailed tests (control variables), one-tailed test (culture of companionate love).

Table 10

Longitudinal Models Predicting Employee Engagement and Withdrawal at Time 2 from Culture of Companionate Love Artifacts at Time $1^{*}$

\begin{tabular}{lllll}
\hline & $\begin{array}{l}\text { Time } 2 \\
\text { Employee } \\
\text { Emotional } \\
\text { Exhaustion }\end{array}$ & $\begin{array}{l}\text { Time } 2 \\
\text { Employee } \\
\text { Absenteeism }\end{array}$ & $\begin{array}{l}\text { Time } 2 \\
\text { Employee } \\
\text { Teamwork }^{\mathrm{c}}\end{array}$ & $\begin{array}{l}\text { Time } 2 \\
\text { Employee } \\
\text { Satisfaction }^{\mathrm{a}}\end{array}$ \\
& $-.95 \bullet$ & $-1.08 \bullet$ & $.91 \bullet$ & $.76 \bullet$ \\
\hline Site 1 1 Predictor Variables & $-.72 \bullet$ & -.62 & $.69 \bullet$ & .52 \\
Site 2 & -.30 & -.01 & $.35 \bullet$ & $.32 \bullet$ \\
Male & .00 & .00 & .00 & .00 \\
Tenure & .01 & $.51 \bullet \bullet$ & .11 & -.06 \\
Certified nursing assistant (CNA) & $-.29 \bullet$ & -.04 & .05 & .06 \\
Trait positive affectivity (PA) & $-1.68 \bullet$ & -.24 & $1.31 \bullet \bullet$ & $1.40 \bullet \bullet$ \\
Social desirability & $-.48 \bullet \bullet$ & $-.38 \bullet \bullet$ & $.55 \bullet \bullet$ & $.44 \bullet \bullet$ \\
Culture of companionate love - & & & & .16 \\
$\quad$ Artifacts (Time 1) & .17 & .09 & .12 & .16 \\
Pseudo R & & & & \\
\hline
\end{tabular}

*Unstandardized coefficients are reported. Time 2 measures collected 16 months later. ${ }^{a} \mathrm{n}=137$ observations

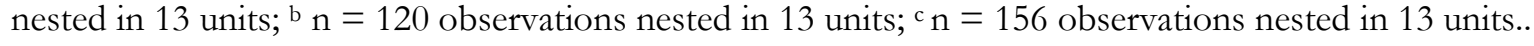
$\bullet \mathrm{p}<.05, \cdots \mathrm{p}<.01, \cdots \mathrm{p}<.001$, two-tailed tests (control variables), one-tailed test (culture of companionate love). 


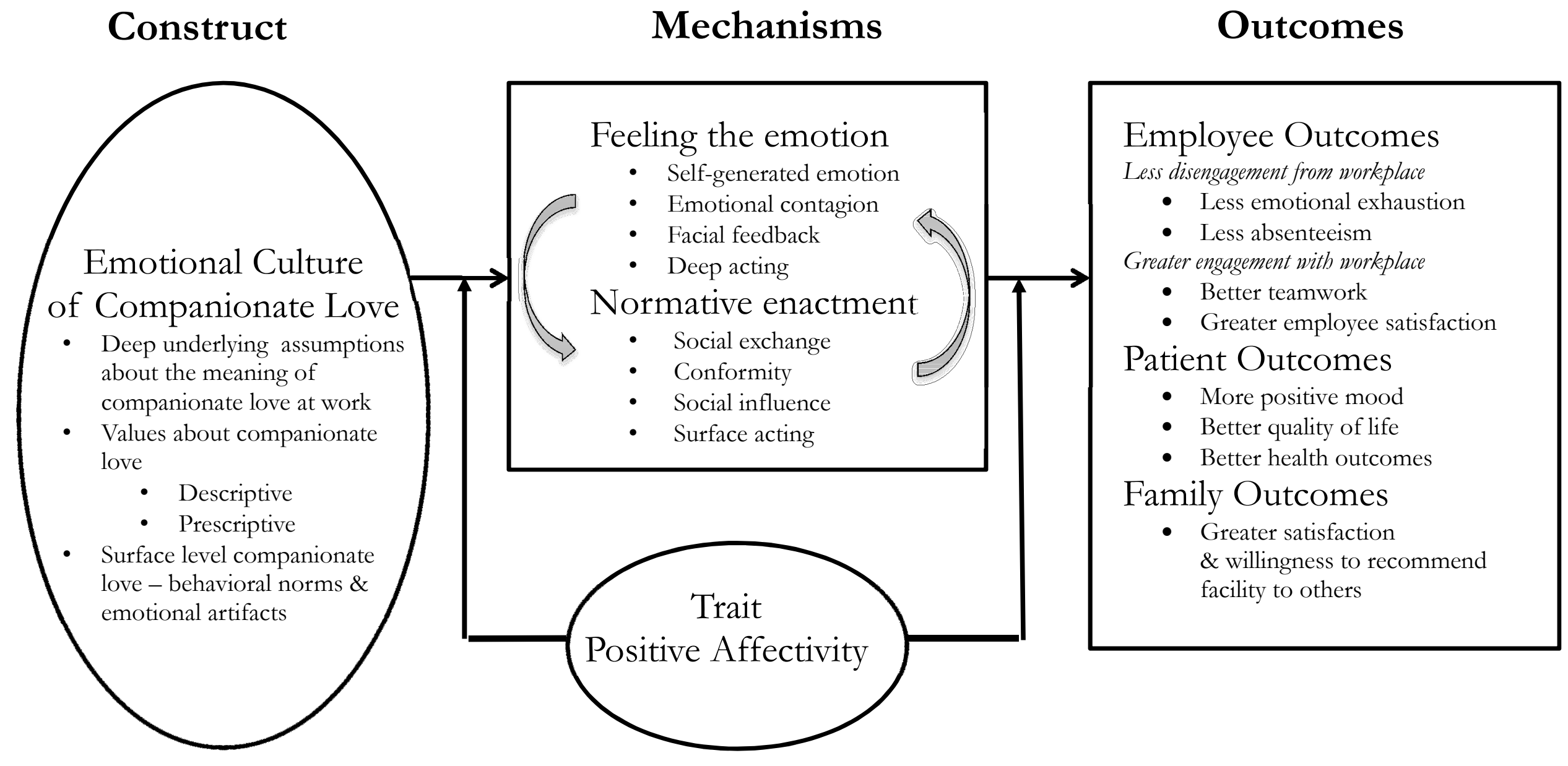

Figure 1: Theoretical Model of Emotional Culture of Companionate Love 


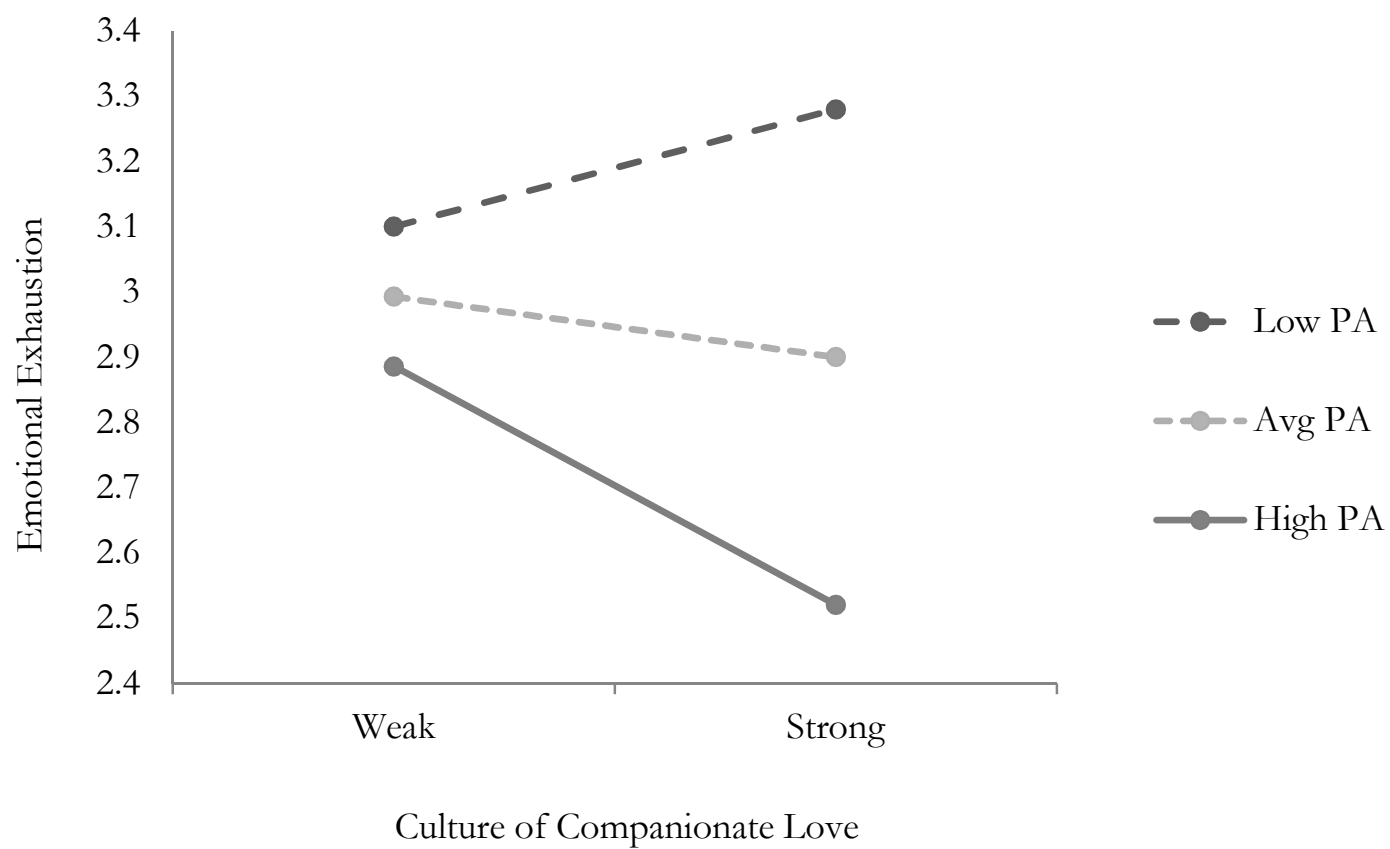

Figure 2: Interaction of a culture of companionate love and trait positive affect (PA) on employee emotional exhaustion. 


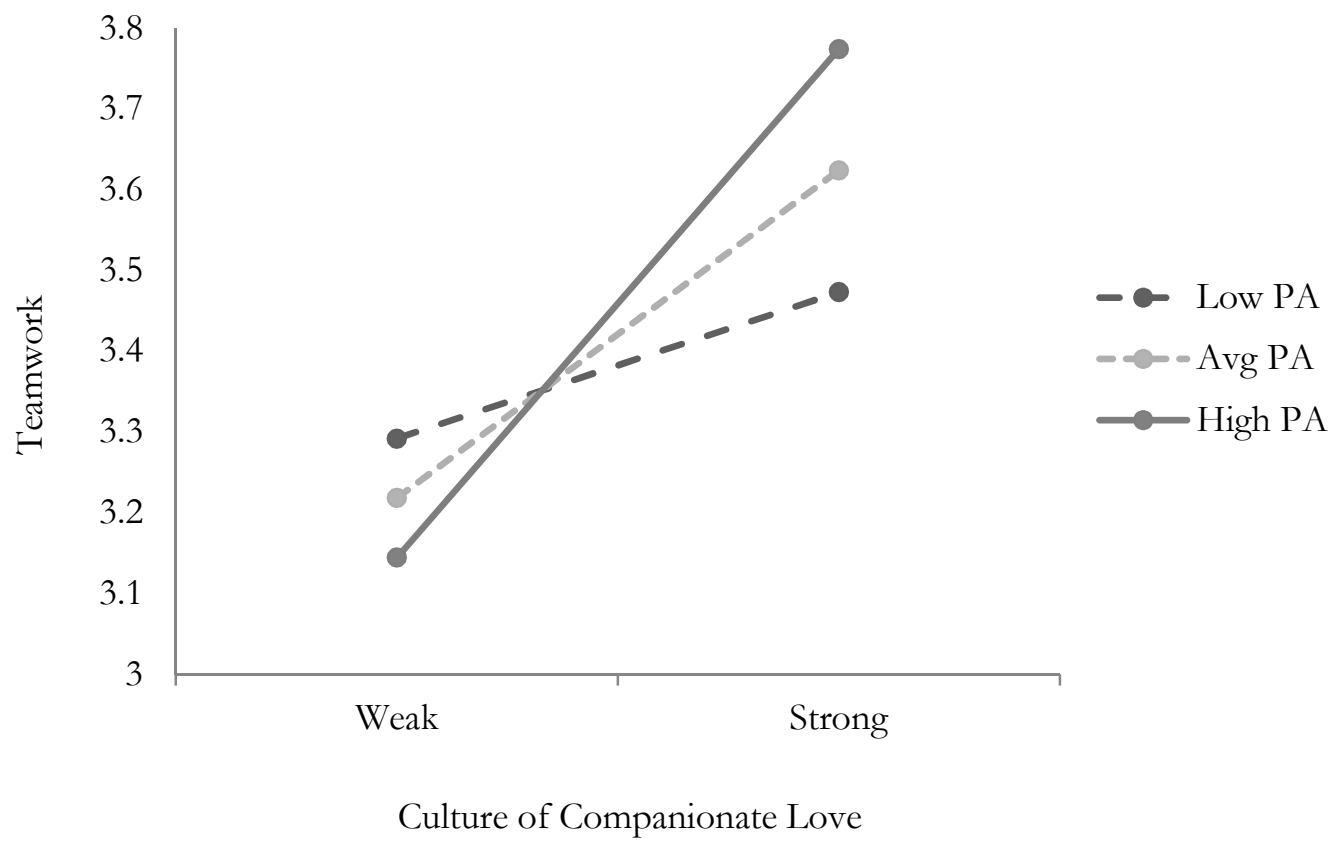

Figure 3: Interaction of a culture of companionate love and trait positive affect on employee teamwork.

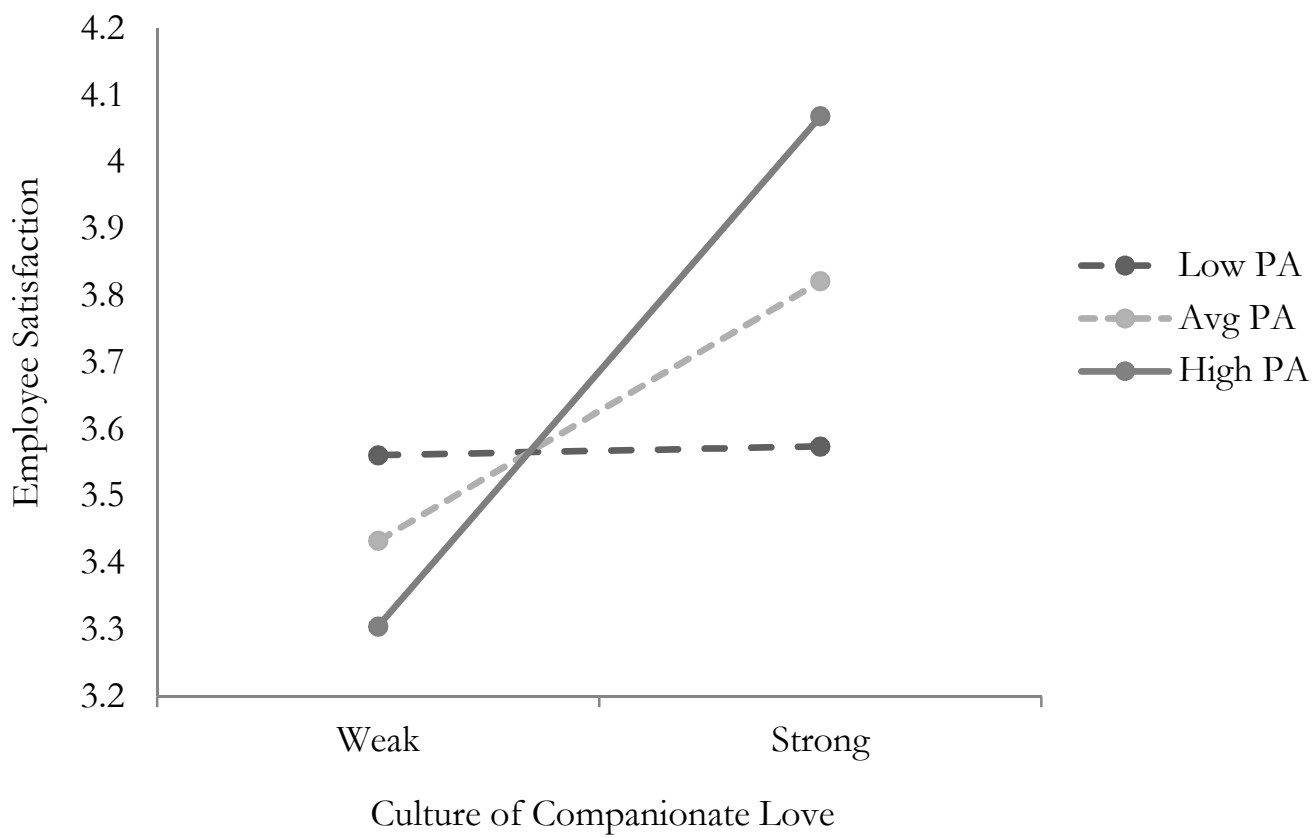

Figure 4: Interaction of a culture of companionate love and trait positive affect on employee satisfaction 


\section{Appendix A: Satisfaction Scales}

Employee Organizational Satisfaction Scale modified from the Alliance Continuing Care Network of Long Term Care Facilities (2004):

I would recommend the services of this organization to family member or friend.

At work my opinion seems to count.

I am comfortable seeking the help I need from my supervisor.

I am provided with the proper tools and equipment to do my job.

The actions and decisions within our organization support our mission and values.

I feel valued as an employee.

My supervisor treats me with respect.

Overall I am satisfied working here.

I am proud to work here.

I would recommend my unit as a good place to work.

Resident (Patient) Satisfaction Scale from the from the Alliance Continuing Care Network of Long Term Care Facilities (2004):

Overall, how satisfied are you with the care you receive from the following individuals:

Primary care doctor, Nurse, Nursing assistant, Social worker, Recreation therapist, Dietician

Overall, how satisfied are you with:

the respect and courtesy you receive?

your level of participation in the decisions about your care?

the safety and security of your belongings?

your personal safety and security?

the cleanliness of your room and bathroom?

how well your pain is managed and/or controlled?

Family Satisfaction Scale from the Alliance Continuing Care Network of Long Term Care Facilities (2004):

Overall, how satisfied are you with the care you receive from the following individuals:

Billing/Finance, Dietician, Food Services, Front Desk Reception, Grounds Maintenance,

Housekeeping/Building Services, Laundry Services, Nursing Assistant/Aide, Nurse, Physician,

Recreation Therapist, Rehabilitation Therapist, Security, Social Worker

Overall, how satisfied are you with the extent to which:

You are familiar with staff members who care for your family member/friend?

The staff interacts appropriately with the residents?

You are kept apprised and informed about your family member/friend's care plan?

You are kept up to date about significant changes in the health of your family member/friend?

Your family member/friend's heath information is kept private and confidential?

Your family member/friend's belongings are free from loss or use by others?

Your family member/friend is kept safe and secure?

Your family member/friend has access to spiritual/spiritual care?

The facility is clean and well maintained in its appearance?

The physical appearance and hygiene of the residents is maintained?

Your family member/friend is engaged appropriately in activities and recreation?

Your family member/friend is treated with respect and able to maintain a sense of dignity?

A quiet and peaceful space is available to your family member/friend?

Your family member/friend's pain is managed and controlled? 


\section{Appendix B: Control Variables}

Certified nursing assistants. Certified nursing assistants (CNAs) are paraprofessional employees who differ from other staff in that they provide the vast majority of the hands-on care (including feeding, dressing, toileting, and grooming) for long-term care facility residents (Pennington, Scott, and Magilvy, 2003). Because CNAs have been found to be less satisfied and have greater turnover than other long-term care facility employees (Decker et al., 2003), we control for whether an employee was a CNA.

Employee Tenure. Tenure data were provided by the organization's human resource department. We defined employee tenure as the number of months the employee had been employed by the organization at the start of the study at Time 1. Please see Table 1 for statistical descriptives of employee characteristics.

Employee Time 1 Social Desirability. Despite the fact that employees were notified that study results were completely confidential (held only by the researchers), we controlled for the possibility that employees might give responses that make themselves look good to the organization. To eliminate this source of error, we used the Marlowe-Crowne Social Desirability Scale (Crowne and Marlowe, 1960), with its 11 items measured on a true-false scale $(\mathrm{M}=.86$, s.d. $=0.14$, Cronbach Alpha $=.53) \cdot{ }^{6}$

Geographic Site. This long-term healthcare facility consists of three different geographic sites. The geographic sites are similar on key structural and population dimensions; however, in case other differences between the three sites influence outcomes, we control for geographic site. To do so, we include dummy variables for the three units. $42.5 \%$ of the employees worked at Site 1,39\% worked at Site 2, and 18.5\% worked at Site 3.

Male. Employees reported their sex as a dichotomous item ( $0=$ Female, $1=$ Male $)$ on the employee survey. We used hospital records to obtain information about the sex of patients. Please see Table 1 for employee and patient characteristics.

Organizational Change Units. During the time period of this study, the long-term healthcare facility undertook an organizational change; this change was part of a growing movement to transform long-term healthcare organizations from a medically-focused, hospital model to one focused on the quality of life of the patients (Weiner

\footnotetext{
${ }^{6}$ Since the reliability of this social desirability measure was low, at Time 2 we measured social desirability with the same 11 items measured on a $1-5$ scale $(1=$ Strongly Disagree through $5=$ Strongly Agree $)(M=1.89$, s.d. $=0.51)$ and reached a more acceptable Cronbach Alpha of .73. While all analyses here are reported with the Time 1 Social Desirability, we reanalyzed analyses with the Time 2 social desirability and all results remained the same.
} 
and Ronch, 2003). As part of this change, the organization aimed to increase respect for its employees through greater involvement in decision-making on the unit and by paying attention to their ideas and encouraging creative suggestions. Because seven of the thirteen units were part of the organizational change, we controlled for this variable in all analyses, but found no significant relationships or difference in the outcomes of the analyses.

Patient-Health and Physical Functioning. For patient analyses, we controlled for the influence of factors commonly used in the gerontology literature to assess health and functioning. We collected this data at Time 2 (rather than Time 1) because the patients' more proximal health functioning could have a large influence on their well-being and health outcomes. All data for these variables was collected from the Minimum Data Set system, a standardized tool required as part of the record keeping by this long-term facility, used by most long-term care facilities for “...implementing standardized assessment and for facilitating care management in nursing homes” (CMS.gov website, 2009). The three patient health factors were:

(1) Poor cognitive functioning $(\mathrm{M}=2.91$, s.d. $=2.06)$, a composite score derived from assessments of cognitive decision-making skills, short-term memory, and ability to make oneself understood, each measured on a 0 7 scale $(0=$ intact and $6=$ very severe impairment; see Morris et al., 1994);

(2) Poor physical functioning, a measure of a patient's ability in mobility, transfer, eating and toileting. Employees rated each of these measures of patients' overall physical functioning on a $0-4$ scale $(0=$ Independence to 4 $=$ Total Dependence; see Huang, et. al. 2003); overall physical functioning was the sum of all these measures for each patient with scores ranging from 0 to 16 , and a mean of 8.79 (s.d. $=5.38$ );

(3) Poor health ( $\mathrm{M}=4.32$, s.d. $=1.88)$, which was calculated as the sum of how many of 43 possible illnesses and diseases listed in the MDS with which the patient was diagnosed at Time 2. 